\title{
Effect of Pneumatic Boxing Gloves on Impact Kinematics and Their Relationship to Impact Forces
}

\author{
Paul Perkins' 1,2, Alex Jamieson1, Wayne Spratford1, Allan Hahn"1,3,4 \\ ${ }^{1}$ University of Canberra Research Institute for Sport \& Exercise, Canberra, Australia \\ ${ }^{2}$ Boxing Australia Limited, Canberra, Australia \\ ${ }^{3}$ Queensland Academy of Sport, Brisbane, Australia \\ ${ }^{4}$ Griffith University, Brisbane, Australia \\ Email: paul.perkins@uni.canberra.edu.au
}

How to cite this paper: Perkins, P., Jamieson, A., Spratford, W. and Hahn, A. (2019) Effect of Pneumatic Boxing Gloves on Impact Kinematics and Their Relationship to Impact Forces. World Journal of Engineering and Technology, 7, 472-512. https://doi.org/10.4236/wjet.2019.73035

Received: July 22, 2019

Accepted: August 17, 2019

Published: August 20, 2019

Copyright (c) 2019 by author(s) and Scientific Research Publishing Inc. This work is licensed under the Creative Commons Attribution International License (CC BY 4.0).

http://creativecommons.org/licenses/by/4.0/

\section{Open Access}

\begin{abstract}
This study was aimed at improved understanding of the mechanisms of previously reported protective effects of a pneumatic boxing glove. A Motion Capture System was used to obtain velocity data from four different boxing gloves dropped on to a force plate from nine heights ranging from 1 to 5 metres. Two gloves were of the conventional type but differed in mass. The other two were prototype pneumatic gloves. One of these (SBLI) had a sealed bladder while the other (ARLI) incorporated a port allowing air exchange with the external environment. The pneumatic gloves decelerated more slowly than the conventional gloves following impact and compressed through a greater absolute distance. Consequently, they took longer to reach zero velocity. As drop height increased, these trends became more pronounced for the ARLI glove than the SBLI glove. Increase in velocity during rebound was also slower for the pneumatic gloves. The ARLI glove had a lower coefficient of restitution than any of the other gloves at low to moderate drop heights but not at high drop heights. The SBLI glove had a higher coefficient of restitution than the other gloves at all drop heights from 2 metres upwards. This indicated that, overall, the ARLI glove was the most effective, and the SBLI glove the least effective, in dissipating the kinetic energy of impact through conversion to other energy forms. For all gloves at all drop heights, peak positive acceleration at the beginning of rebound was of lower absolute magnitude than peak negative acceleration at the end of compression. The influence of drop height on an index characterising this relationship differed between the conventional and pneumatic gloves, possibly reflecting structural changes to gloves as impact energy increased. The conventional and pneumatic gloves
\end{abstract}


differed regarding temporal alignment between key kinematic and kinetic events, and there were some differences between the two pneumatic gloves in this respect. Nevertheless, peak glove deceleration correlated highly with peak impact force, not only for each glove individually but also when data for all gloves were combined. The findings confirmed the potential practical utility of the ARLI glove and identified air cushion thickness, glove compressibility and capacity for air release and subsequent reuptake as critical aspects of its design.

\section{Keywords}

Pneumatic Boxing Gloves, Boxing Safety, Modified Boxing, Sport Safety, Sport Technology, Sports Equipment Design, Coefficient of Restitution, Elastic-Plastic Impacts

\section{Introduction}

We have recently published a series of papers demonstrating that a pneumatic boxing glove incorporating capacity for air exchange with the external environment can substantially reduce peak impact forces and loading rates compared to those obtained with a conventional boxing glove striking a target at similar velocity [1] [2] [3] [4]. This is true across a range of peak pre-impact glove velocities extending from $\sim 4.4$ to $\sim 10.0 \mathrm{~m} \cdot \mathrm{sec}^{-1}$, with the latter velocity approximating the maximum level that reportedly can be generated by elite boxers [5] [6] [7].

Thorough understanding of the mechanism by which the pneumatic glove exerts its protective effect could provide a basis for eventual enhancement of that effect. Our studies have shown that the pneumatic glove prolongs contact time with the target [1] [2] [3] [4] and the time from initial contact to occurrence of peak impact force [4]. Distribution of a given impact impulse over a longer time could be expected to reduce both average and peak force. A question arises, however, as to whether there are other contributors to peak force reduction. In one of our published experiments [4], we found that over a series of 250 drops on to a force plate from a height of 3 metres there was progressive upward drift in peak force and loading rate for both a pneumatic glove and a conventional $10 \mathrm{oz}$ glove, with the magnitude of drift less for the pneumatic glove. In the case of the conventional glove, $\sim 96 \%$ of the variance in peak force could be explained by variance in contact time, with peak force increasing as contact time decreased. Although the relationship was of the same direction for the pneumatic glove, it was very much weaker, with variance in contact time explaining only $\sim 9 \%$ of the variance in peak force.

Time from initial force plate contact to occurrence of peak force was a better predictor of peak force for the pneumatic glove, but still accounted for only 59\% of the variance, while the corresponding figure for the conventional glove was $\sim 92 \%$. This suggested that the effect of the pneumatic glove on peak force was 
perhaps importantly influenced by factors other than just contact time or one of its components, the time to peak force.

During our early studies with the pneumatic gloves [1] [2], we measured glove velocities, primarily with a view to confirming that peak pre-impact velocities matched our theoretical calculations. In view of the above, we decided to undertake more detailed analysis of the velocity data obtained after glove contact with the force plate. We reasoned that this analysis might yield further insights into determinants of glove performance, particularly when integrated with other observations. Specifically, we envisaged that calculating coefficients of restitution [8] [9] [10] [11] for the different glove types could be useful as a means of estimating the extent of conversion of some of the kinetic energy of impact to other energy forms.

This paper describes the outcomes of the further analysis.

\section{Methods}

The data capture protocol is fully described elsewhere [1]. Two prototype pneumatic gloves and two conventional gloves were tested. One of the pneumatic gloves had a fully sealed bladder and is hereafter identified by the abbreviation SBLI. The other had a resilient bladder incorporating a port that enabled release of air to the external environment upon impact and subsequent air reuptake. It is hereafter identified by the abbreviation ARLI. The pneumatic gloves were manufactured by Stellen Studio (Canberra, Australia).

The conventional gloves were produced by Sting Sports (Melbourne, Australia). One had a designated mass of $10 \mathrm{oz}$ and the other a designated mass of $16 \mathrm{oz}$. Gloves of these masses are commonly used by boxers for competition and sparring respectively [12] [13]. The $10 \mathrm{oz}$ glove is hereafter termed Std $10 \mathrm{oz}$ and the 16 oz glove is termed Std 16 oz.

Actual mass, as measured with digital kitchen scales, was $227 \mathrm{~g} \mathrm{(8.0} \mathrm{oz)} \mathrm{for} \mathrm{the}$ SBLI glove, $298 \mathrm{~g}(10.5 \mathrm{oz})$ for the ARLI glove, $278 \mathrm{~g}(9.8 \mathrm{oz})$ for the Std $10 \mathrm{oz}$ glove and $455 \mathrm{~g}(16.0 \mathrm{oz})$ for the Std $16 \mathrm{oz}$ glove.

Each glove was placed on a specially constructed mechanical fist with a mass of $3.046 \mathrm{~kg}$ and dropped on to a $600 \mathrm{~mm} \times 400 \mathrm{~mm}$ Kistler in-floor force plate (Kistler, Amherst, MA) 9 - 11 times from each of nine different heights ranging from 1 - 5 metres. The force plate was covered by a mat consisting of a $25 \mathrm{~mm}$ thickness of ethyl vinyl-acetate (EVA) foam (Ultralon Foam Group, Sydney, Australia).

A Vicon Motion Capture System (Oxford Metrics Ltd, Oxford, UK) with four cameras each sampling at 500 frames per second was used to determine glove velocities just before and after impact with the force plate. Three markers placed on each glove enabled determination of displacement and thus calculation of velocity over successive 2-msec time periods. Data from the four cameras were integrated to ensure accuracy of the calculations.

Collection of data from the force plate (at a sampling rate of $10,000 \mathrm{~Hz}$ ) was 
accomplished via Vicon Nexus software, permitting synchronisation of trajectory and force plate data.

The testing of the gloves was conducted over two sessions separated by eight days. In the first session, drop heights ranged from 1.0 to 3.5 metres. For each glove, the initial drop height was 2.0 metres, and we then progressed sequentially to $2.5,1.5,1.0,3.0$ and 3.5 metres. The Std $10 \mathrm{oz}$ glove was tested first, followed by the SBLI, ARLI and Std $16 \mathrm{oz}$ gloves. In the second session, the order of drop test heights was 4.0, 4.5 and 5.0 metres, and the order of glove testing was ARLI, Std $10 \mathrm{oz}$, Std $16 \mathrm{oz}$, SBLI. In both sessions, each glove was tested at all drop heights before progression to the next glove.

Statistical analysis of the data was performed using GraphPad Prism software (GraphPad Software Inc, California, USA).

\section{Results}

Mean velocity curves derived from 9 - 11 trials per glove at each drop height are presented in Figure 1. The curves reflect a period extending from just before impact to just after attainment of maximum rebound velocity. In each instance, the downward phase indicates slowing of the glove as it compresses following contact with the force plate and the upward phase represents increasing velocity as the glove rebounds. These phases are hereafter termed the compressive and rebound phases respectively. They are examined in more detail below, and consideration is then given to relationships between glove velocity measurements and force plate data.

\subsection{Compressive Phase of Velocity-Time Curve}

\subsubsection{Duration of Compressive Phase}

Figure 1 shows that during the compressive phase of glove impact with the force plate, the velocity of the SBLI and ARLI gloves declined more slowly than that of the Std $10 \mathrm{oz}$ and Std $16 \mathrm{oz}$ gloves. This was true at all drop heights, although when the SBLI glove was dropped from 5 metres its difference from the conventional gloves was marginal.

The restriction of our sampling rate to $500 \mathrm{~Hz}$, combined with the averaging process used to derive the curves presented in Figure 1, meant that the minimum recorded glove velocities were always above zero, but the gloves obviously must have reached zero velocity at some point.

To estimate the time to occurrence of zero glove velocity, second order polynomial regression equations were calculated for the compressive component of the velocity-time curve for every glove drop, with care taken to ensure that in each case the lowest included velocity reading was unequivocally part of that component. Fitting of the equations to the raw data yielded mean $\mathrm{R}^{2}$ values of 0.9997 (range $=0.9950-0.9999), 0.9990$ (0.9949 - 0.9998), $0.9996(0.9989-0.9999)$ and 0.9996 (0.9987 - 0.9999) for the SBLI, ARLI, Std 10 oz and Std 16 oz gloves respectively. We therefore felt justified in using the equations to extrapolate to the point of zero velocity and determine the associated time. 
(a) 1 metre

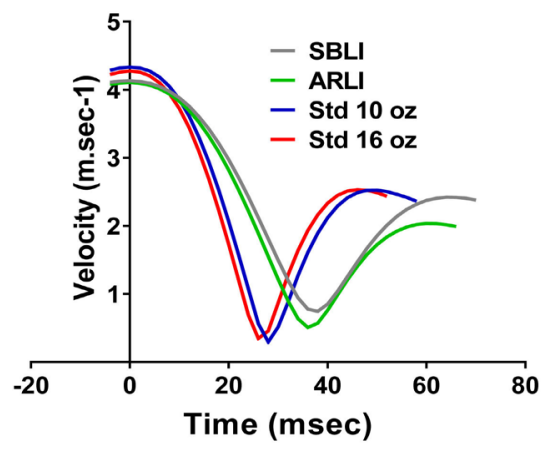

(d) 2.5 metres

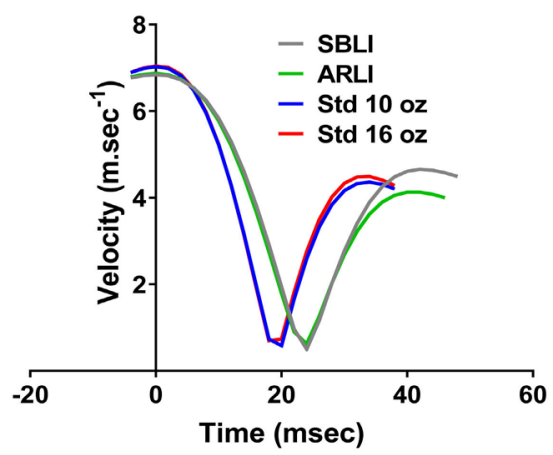

(g) 4 metres

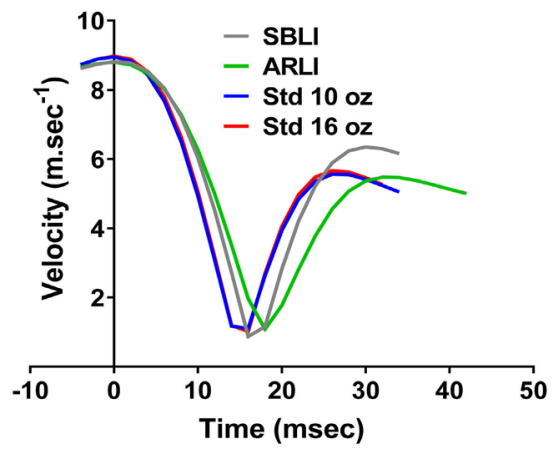

(b) 1.5 metres

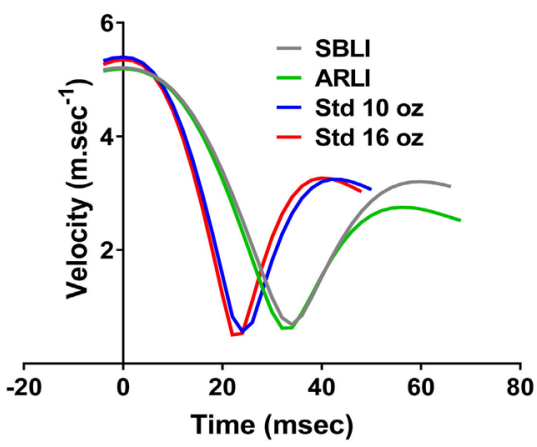

(e) 3 metres

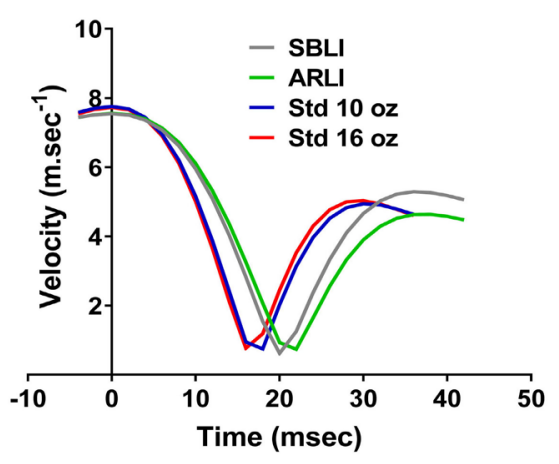

(h) 4.5 metres

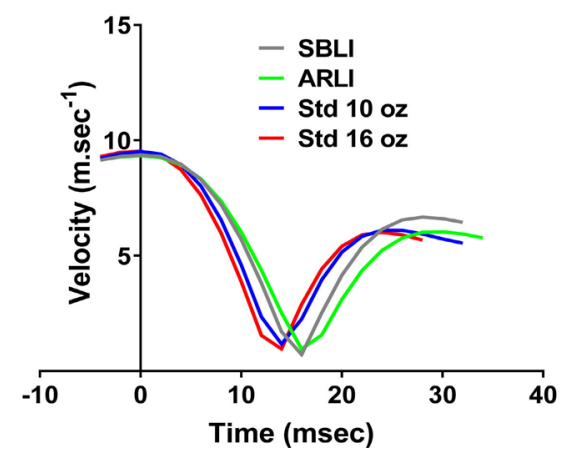

(c) 2 metres

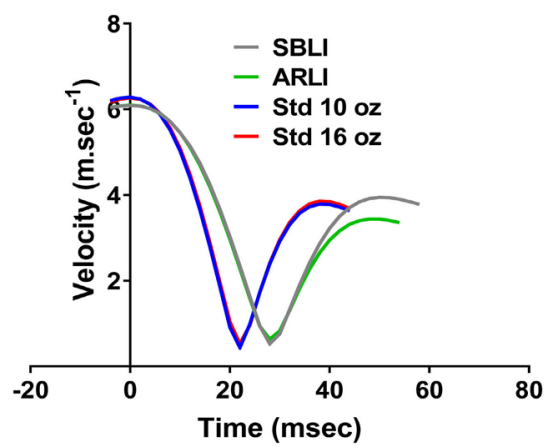

(f) 3.5 metres

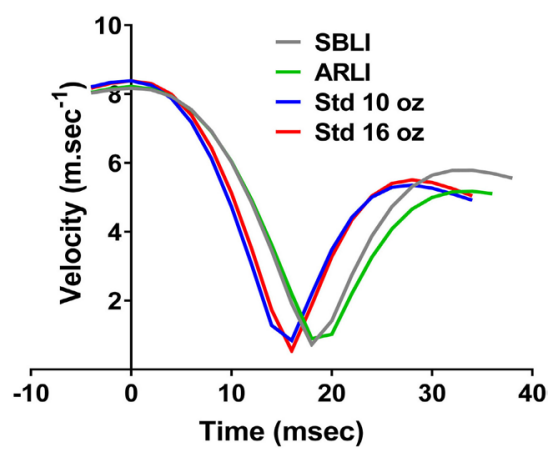

(i) 5 metres

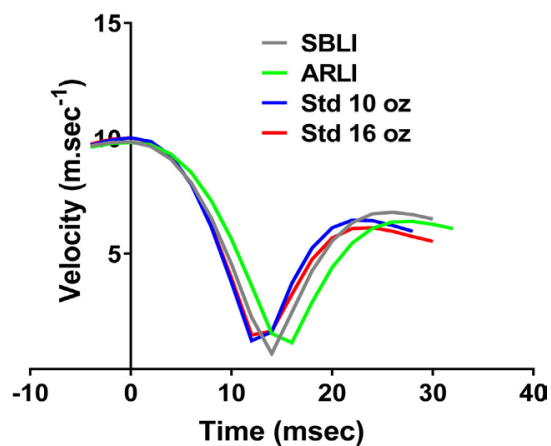

Figure 1. Changes in velocity for four different boxing gloves dropped on to a force plate from heights ranging from 1 to 5 metres. Each curve is based on mean readings derived from 9 - 11 glove drops and covers a period from just before glove contact with force plate to just after the attainment of peak rebound velocity. The sampling rate was $500 \mathrm{~Hz}$.

Mean times to zero velocity calculated by this method turned out to be quite close to the mean times of occurrence of the minimum recorded velocity, as shown in Figure 2. This suggests that some of the minimum recorded velocities preceded the zero-velocity point while others succeeded it, with the discrepancies largely cancelling each other out.

The curves shown in Figure 2, however, are not absolutely overlaid, meaning that the difference between calculated time to zero velocity and the observed time of minimum glove velocity varied slightly between glove types. Hence, when all glove drops from all drop heights were included, mean values for a parameter obtained by subtracting the latter time from the former were $0.03 \mathrm{msec}$ 


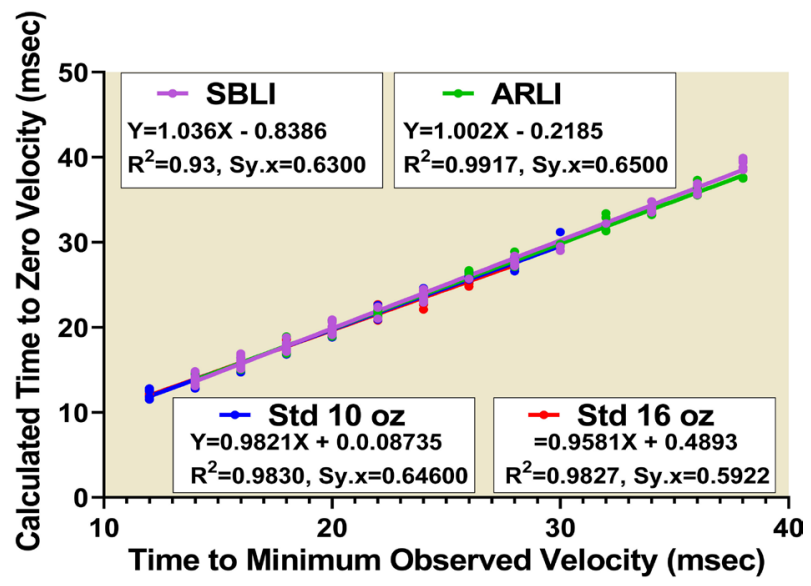

Figure 2. Relationship between time from first glove contact with force plate to occurrence of zero glove velocity (as calculated from second-order polynomial regression equations) to minimum glove velocity observed with a sampling rate of $500 \mathrm{~Hz}$.

(95\% confidence interval -0.18 to $+0.12 \mathrm{msec}$ ) for the SBLI glove, $-0.18 \mathrm{msec}$ ( -0.31 to -0.04$)$ for the ARLI glove, $-0.24 \mathrm{msec}(-0.38$ to -0.11$)$ for the Std 10 oz glove and $-0.28 \mathrm{msec}(-0.41$ to -0.15$)$ for the Std $16 \mathrm{oz}$ glove. We therefore faced a decision on whether to proceed with use of the times calculated from the regression equations or to employ times associated with minimum observed glove velocity as surrogates of the time to zero velocity. We chose the regression option on the grounds that it was explicitly focused on accurate determination of time to zero velocity rather than depending on a zero sum of errors produced by a surrogate method. It also allowed the time to zero velocity to be calculated to a resolution of $0.1 \mathrm{msec}$ for every glove drop, whereas raw data points were $2 \mathrm{msec}$ apart, with greater resolution possible only through data averaging. For this reason, the regression approach produced less variable data, as reflected by lower standard deviations. Finally, the differences in the mean results produced by the two approaches were small in the context of a situation where time to zero velocity was always above $10 \mathrm{msec}$ (see Figure 2).

Times to zero velocity calculated by the regression method are presented in Figure 3. At every drop height, the velocity declined to zero more slowly for the two pneumatic gloves than for the standard gloves. The mean time to zero velocity was longest for the SBLI glove at drop heights up to and including 2.5 metres, but thereafter it was longest for the ARLI glove. Two-way analysis of variance (ANOVA) revealed that drop height accounted for $79.0 \%$ of the variation in the data set, glove type for $13.5 \%$ and interaction between drop height and glove type for 5.7\%, with each of these effects being statistically significant $(\mathrm{P}<$ 0.0001 ). Only $1.8 \%$ of the variance was residual, meaning that it could not be attributed to any of these factors. The results of subsequent Tukey post-hoc comparisons are presented in Table 1. At every drop height the time to zero velocity was significantly longer for the ARLI glove than for either of the conventional gloves. The same was true when the SBLI glove was compared to the conventional gloves, except at a drop height of 5 metres. Statistically significant differences 


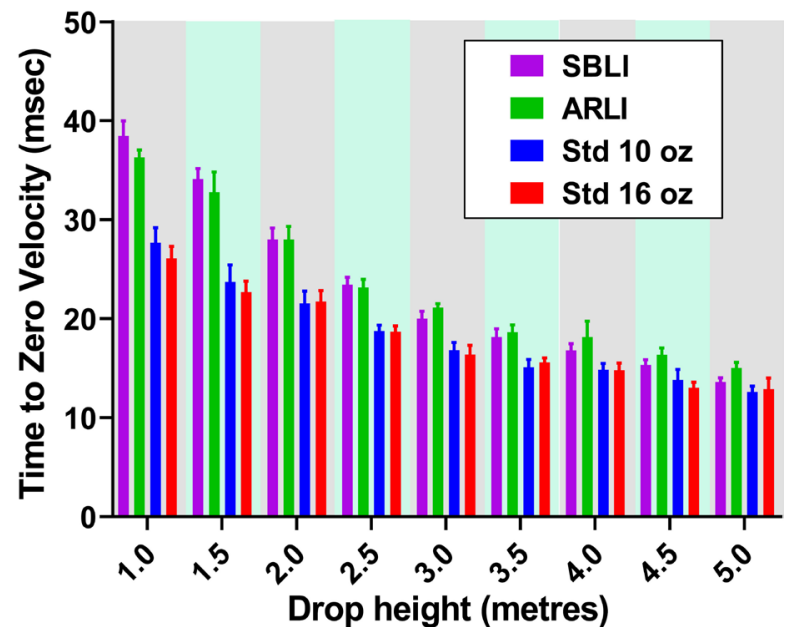

Figure 3. Time from glove contact with force plate to attainment of zero glove velocity for four different gloves. Each bar depicts a mean value derived from 9 - 11 glove drops, and standard deviations are also shown. Times were calculated to a resolution of $0.1 \mathrm{msec}$ using second-order polynomial regression equations based on data collected at a sampling frequency of $500 \mathrm{~Hz}$.

Table 1. Results of Tukey post-hoc comparisons between glove types for calculated time to zero glove velocity at various drop heights. Each cell shows the probability that there was no real difference between glove types. Red figures indicate a statistically significant difference and blue figures indicate absence of significance $(P>0.05)$.

\begin{tabular}{ccccccc}
\hline $\begin{array}{c}\text { Drop } \\
\text { height }(\mathbf{m})\end{array}$ & $\begin{array}{c}\text { SBLI } \\
\text { vs } \\
\text { ARLI }\end{array}$ & $\begin{array}{c}\text { SBLI } \\
\text { vs } \\
\text { Std 10 oz }\end{array}$ & $\begin{array}{c}\text { SBLI } \\
\text { vs } \\
\text { Std 16 oz }\end{array}$ & $\begin{array}{c}\text { ARLI } \\
\text { vs } \\
\text { Std 10 oz }\end{array}$ & $\begin{array}{c}\text { ARLI } \\
\text { vs } \\
\text { Std 16 oz }\end{array}$ & $\begin{array}{c}\text { Std 10 oz vs } \\
\text { Std 16 oz }\end{array}$ \\
\hline 1.0 & $<0.0001$ & $<0.0001$ & $<0.0001$ & $<0.0001$ & $<0.0001$ & 0.026 \\
1.5 & 0.0248 & $<0.0001$ & $<0.0001$ & $<0.0001$ & $<0.0001$ & 0.0971 \\
2.0 & $>0.9999$ & $<0.0001$ & $<0.0001$ & $<0.0001$ & $<0.0001$ & 0.9724 \\
2.5 & 0.9318 & $<0.0001$ & $<0.0001$ & $<0.0001$ & $<0.0001$ & 0.9989 \\
3.0 & 0.0744 & $<0.0001$ & $<0.0001$ & $<0.0001$ & $<0.0001$ & 0.7360 \\
3.5 & 0.7222 & $<0.0001$ & $<0.0001$ & $<0.0001$ & $<0.0001$ & 0.6960 \\
4.0 & 0.0133 & 0.0001 & $<0.0001$ & $<0.0001$ & $<0.0001$ & 0.9995 \\
4.5 & 0.1143 & 0.0052 & $<0.0001$ & $<0.0001$ & $<0.0001$ & 0.2851 \\
5.0 & 0.0100 & 0.1418 & 0.4294 & $<0.0001$ & $<0.0001$ & 0.9172 \\
\hline
\end{tabular}

between the ARLI and SBLI gloves were observed at drop heights of 1 and 1.5 metres, where the time for the SBLI glove was longer, and 4.0 and 5.0 metres, where the times for the ARLI glove were longer. A significant difference between the Std $10 \mathrm{oz}$ and Std $16 \mathrm{oz}$ gloves was recorded only at 1 metre.

Figure 4 displays mean calculated time to zero velocity for the SBLI, ARLI and Std $16 \mathrm{oz}$ gloves as a percentage of that for the Std $10 \mathrm{oz}$ glove. The effects of the pneumatic gloves in prolonging the time were proportionally greatest at drop heights of 1 and 1.5 metres and then declined as drop height increased. The decline was less steep for the ARLI glove than the SBLI glove, and at a drop height of 5 me- 
tres the time for the ARLI glove was still $\sim 120 \%$ of that for the Std 10 oz glove.

\subsubsection{Glove Displacement during Compressive Phase}

Although glove displacement data obtained by the Vicon Motion Capture System provided the basis for calculation of glove velocities that then allowed derivation of the velocity-time regression equations, a limited sampling rate meant that the raw data were insufficient to permit determination of glove displacement during the compressive phase of impact up to a precisely identified end-point. We therefore back-calculated glove displacements from velocity data generated at intervals of $0.1 \mathrm{msec}$ through use of the regression equations. The results related to the period from first contact of the glove with the force plate (as indicated by reduction in glove velocity from the peak pre-impact level) to occurrence of zero glove velocity. They are summarised in Figure 5, which clearly demonstrates that the pneumatic gloves compressed through a greater distance than the conventional gloves. With increases in drop height, all gloves initially showed an increase in displacement. For the conventional gloves this was essentially followed by stabilisation, whereas for pneumatic gloves it was followed by a reduction that was larger for the SBLI

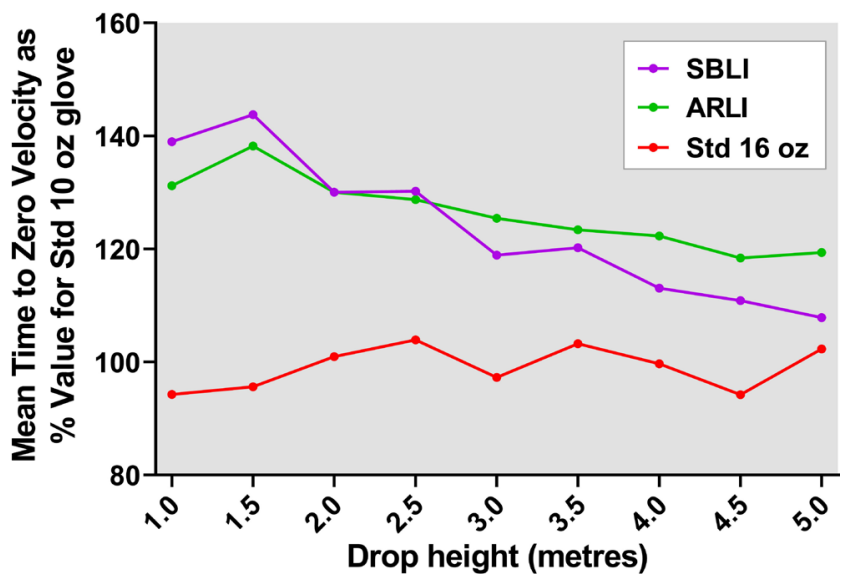

Figure 4. Mean time to zero velocity expressed as percentage of value obtained for the Std 10 oz glove.

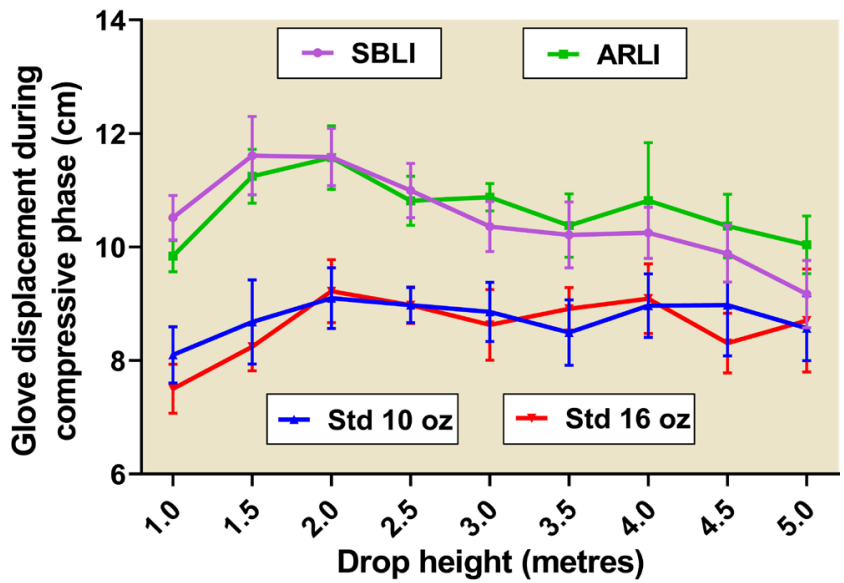

Figure 5. Magnitude of displacement during the compressive phase of impact for different glove types and drop heights. 
glove than the ARLI glove. Two-way ANOVA revealed that $61.3 \%$ of the variance in displacement could be explained by glove type, $11.5 \%$ by drop height and $8.4 \%$ by interaction between glove type and drop height. All these effects were statistically significant $(\mathrm{P}<0.0001)$. Tukey post-hoc comparisons are provided in Table 2 . They show that the ARLI glove compressed significantly more than the conventional gloves at all drop heights, and that this was true also for the SBLI glove except at the 5 -metre drop height. There was a significant difference between the two pneumatic gloves only at 1 metre, where the SBLI glove underwent significantly greater displacement, and at 5 metres, where the displacement was larger for the ARLI glove. There was no consistent statistical difference between the two conventional gloves.

\subsubsection{Glove Acceleration during Compressive Phase}

We used the second order polynomial regression equations describing the compressive phase of glove velocity-time relationships to derive equations expressing relationships between glove acceleration and time. Whereas the velocity equations were quadratic (i.e., of the form $y=a * x^{2}+b * x+c$ ), the acceleration equations were linear $(y=a * x+b)$ and therefore allowed comparison of slopes for the different glove types. For example, for a drop height of 3 metres, a typical velocity equation for the Std $10 \mathrm{oz}$ glove was as follows:

$$
\begin{aligned}
& \operatorname{Velocity}\left(\mathrm{m} \cdot \mathrm{sec}^{-1}\right)=\left(-0.02977 * t^{2}\right)+(0.03894 * t)+7.754, \\
& \text { where } t=\text { time in } \mathrm{msec}
\end{aligned}
$$

The derived acceleration equation was:

$$
\begin{aligned}
& \text { Acceleration }\left(\mathrm{m} \cdot \mathrm{sec}^{-1} \cdot \mathrm{msec}^{-1}\right)=(2 *-0.02977) t+0.03894, \\
& \text { where } t=\text { time in } \mathrm{msec}
\end{aligned}
$$

Use of mean coefficients for each glove type for the drop height of 3 metres

Table 2. Results of Tukey post-hoc comparisons between glove types for calculated magnitude of displacement during compression caused by dropping the gloves on to a force plate from various drop heights. Each cell shows the probability that there was no real difference between glove types. Red figures indicate a statistically significant difference and blue figures indicate absence of significance $(P>0.05)$.

\begin{tabular}{ccccccc}
\hline $\begin{array}{c}\text { Drop } \\
\text { height } \\
(\mathbf{m})\end{array}$ & $\begin{array}{c}\text { SBLI } \\
\text { vs }\end{array}$ & $\begin{array}{c}\text { SBLI } \\
\text { vR }\end{array}$ & $\begin{array}{c}\text { SBLI } \\
\text { vs }\end{array}$ & $\begin{array}{c}\text { ARLI } \\
\text { vs }\end{array}$ & $\begin{array}{c}\text { ARLI } \\
\text { vs }\end{array}$ & $\begin{array}{c}\text { Std 10 oz } \\
\text { vs }\end{array}$ \\
\hline 1.0 & 0.0367 & $<0.0001$ & $<0.0001$ & $<0.0001$ & $<0.0001$ & 0.0808 \\
1.5 & 0.5134 & $<0.0001$ & $<0.0001$ & $<0.0001$ & $<0.0001$ & 0.2969 \\
2.0 & $>0.9999$ & $<0.0001$ & $<0.0001$ & $<0.0001$ & $<0.0001$ & 0.9615 \\
2.5 & $0 . .8834$ & $<0.0001$ & $<0.0001$ & $<0.0001$ & $<0.0001$ & $>0.9999$ \\
3.0 & 0.1689 & $<0.0001$ & $<0.0001$ & $<0.0001$ & $<0.0001$ & 0.7930 \\
3.5 & 0.9174 & $<0.0001$ & $<0.0001$ & $<0.0001$ & $<0.0001$ & 0.3373 \\
4.0 & 0.1082 & 0.0001 & $<0.0001$ & $<0.0001$ & $<0.0001$ & 0.9583 \\
4.5 & 0.2305 & 0.0019 & $<0.0001$ & $<0.0001$ & $<0.0001$ & 0.0393 \\
5.0 & 0.0033 & 0.0773 & 0.2489 & $<0.0001$ & $<0.0001$ & 0.9457 \\
\hline
\end{tabular}


produced the acceleration data depicted in Figure 6.

The negative slopes of the curves shown in Figure 6 reflect the fact that the gloves decelerated after force plate contact. Since the y-intercepts of the curves were close to zero, curve slopes were the primary determinants of the acceleration values. It is visually apparent that the slope was much less steep for the two pneumatic gloves than for the conventional gloves, indicating that the pneumatic gloves decelerated less sharply after impact. Another feature of Figure 6 is that each curve has been extended only to the time point representing the mean time to zero glove velocity for the glove in question. Consequently, the acceleration value corresponding to the rightward endpoint of each curve reflects the peak negative acceleration (deceleration) for that glove. It can be seen that the pneumatic gloves decreased peak glove deceleration.

While the curves presented in Figure 6 are based on mean data, we developed an acceleration equation for each drop of every glove type. Intercepts were always close to zero, never exceeding $0.2 \mathrm{~m} \cdot \mathrm{sec}^{-1} \cdot \mathrm{msec}^{-1}$ for any curve. Data concerning curve slopes are summarised in Figure 7. Two-way ANOVA revealed that $89.7 \%$ of the variance in the data set could be explained by drop height, $6.8 \%$ by glove type and $1.6 \%$ by interaction between drop height and glove type (leaving

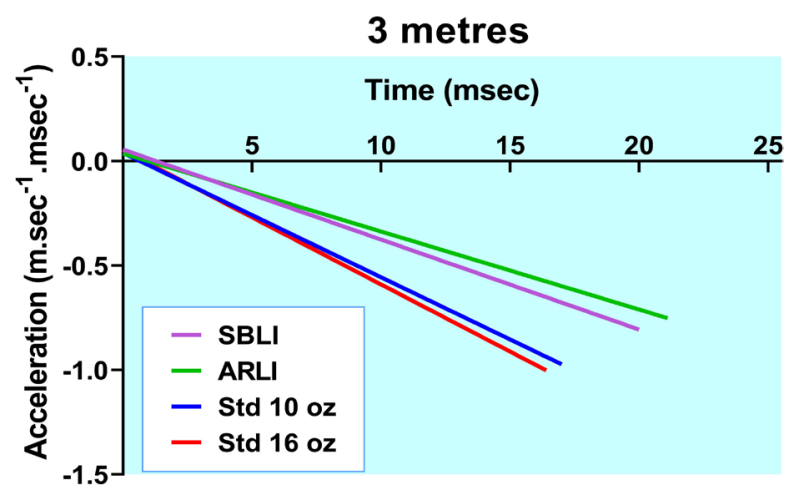

Figure 6. Results of Tukey post-hoc comparisons between glove types for ratio of rebound phase duration to compression phase duration at various drop heights.

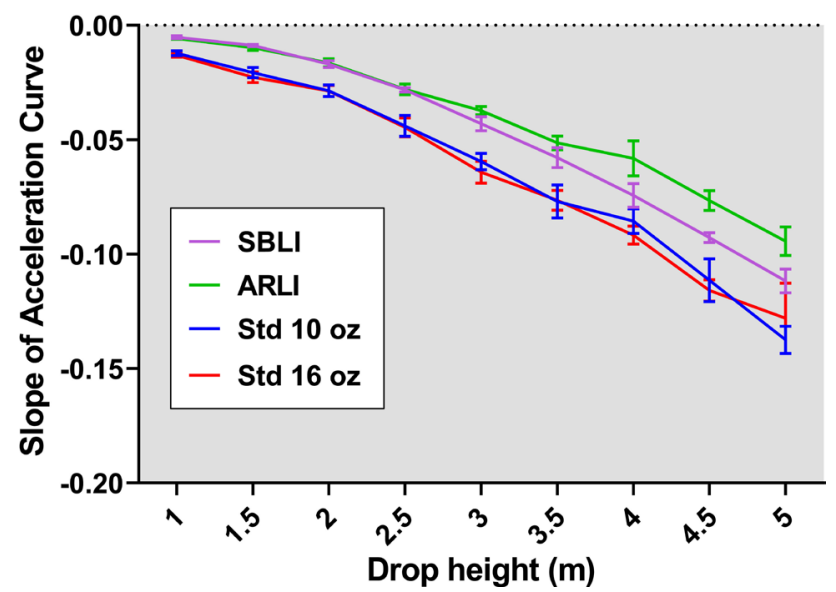

Figure 7. Slope of acceleration-time curves for different glove types and drop heights. Means and standard deviations are shown for series consisting of 9 - 11 glove drops. 
$1.9 \%$ residual variance). The effects of drop height, glove type and the interaction were all statistically significant $(\mathrm{P}<0.0001)$. The results of Tukey post-comparisons between gloves at each drop height are provided in Table 3 . They show that the slopes were always significantly less for the pneumatic gloves than for the conventional gloves, and that the significant interaction term indicated by the two-way ANOVA was largely due to the slopes for the ARLI glove being similar to those for the SBLI glove at drop heights up to and including 2.5 metres but lower at drop heights of 3 metres and above.

In Figure 8, peak negative acceleration values during the compressive phase of glove impact are presented, with means and standard deviations calculated

Table 3. Results of Tukey post-hoc comparisons between glove types for slope of negative glove acceleration between initial glove contact with the force plate and attainment of zero glove velocity. Each cell shows the probability that there was no real difference between glove types. Red figures indicate a statistically significant difference and blue figures indicate absence of significance $(\mathrm{P}>0.05)$.

\begin{tabular}{|c|c|c|c|c|c|c|}
\hline $\begin{array}{l}\text { Drop height } \\
\text { (m) }\end{array}$ & $\begin{array}{l}\text { SBLI } \\
\text { vs } \\
\text { ARLI }\end{array}$ & $\begin{array}{c}\text { SBLI } \\
\text { vs } \\
\text { Std } 10 \mathrm{oz}\end{array}$ & $\begin{array}{c}\text { SBLI } \\
\text { vs } \\
\text { Std } 16 \mathrm{oz}\end{array}$ & $\begin{array}{c}\text { ARLI } \\
\text { vs } \\
\text { Std } 10 \mathrm{oz}\end{array}$ & $\begin{array}{c}\text { ARLI } \\
\text { vs } \\
\text { Std } 16 \mathrm{oz}\end{array}$ & $\begin{array}{c}\text { Std } 10 \mathrm{oz} \\
\text { vs } \\
\text { Std } 16 \mathrm{oz}\end{array}$ \\
\hline 1.0 & 0.9950 & 0.0099 & 0.0020 & 0.0020 & 0.0047 & 0.9825 \\
\hline 1.5 & 0.9654 & $<0.0001$ & $<0.0001$ & $<0.0001$ & $<0.0001$ & 0.7784 \\
\hline 2.0 & 0.9950 & $<0.0001$ & $<0.0001$ & $<0.0001$ & $<0.0001$ & $>0.9999$ \\
\hline 2.5 & 0.9992 & $<0.0001$ & $<0.0001$ & $<0.0001$ & $<0.0001$ & 0.9931 \\
\hline 3.0 & 0.0416 & $<0.0001$ & $<0.0001$ & $<0.0001$ & $<0.0001$ & 0.1267 \\
\hline 3.5 & 0.0203 & $<0.0001$ & $<0.0001$ & $<0.0001$ & $<0.0001$ & 0.99944 \\
\hline 4.0 & $<0.0001$ & $<0.0001$ & $<0.0001$ & $<0.0001$ & $<0.0001$ & 0.0223 \\
\hline 4.5 & $<0.0001$ & $<0.0001$ & $<0.0001$ & $<0.0001$ & $<0.0001$ & 0.1575 \\
\hline 5.0 & $<0.0001$ & $<0.0001$ & $<0.0001$ & $<0.0001$ & $<0.0001$ & $<0.0001$ \\
\hline
\end{tabular}

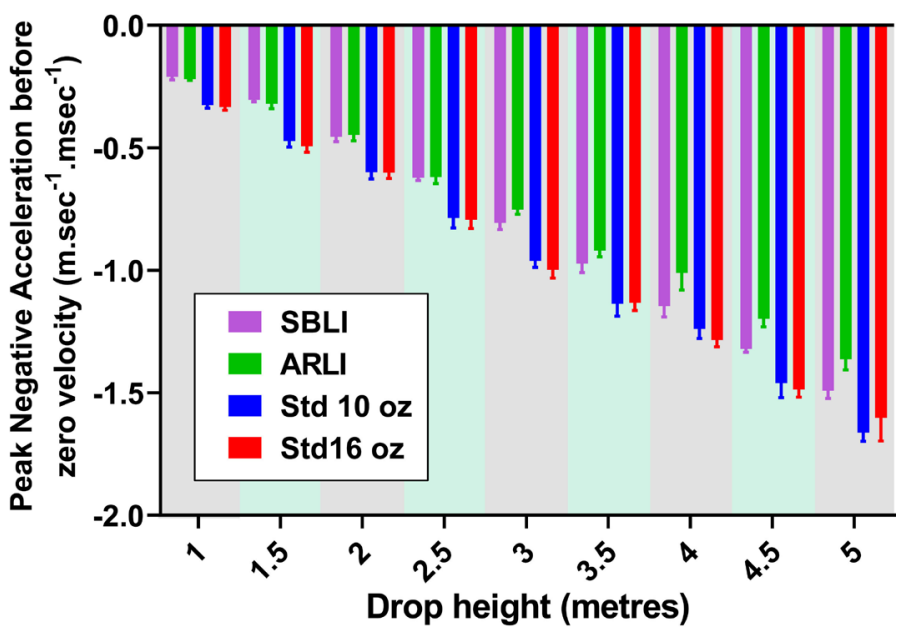

Figure 8. Effect of glove type and drop height on peak rates of negative glove acceleration during period from first contact with force plate to occurrence of zero glove velocity. Means and standard deviations are shown for series consisting of 9 - 11 glove drops. 
from data obtained by use of acceleration-time curves to ascertain the level of negative acceleration reached immediately before the point of zero glove velocity. This was appropriate given that negative acceleration continued to increase linearly right up to that point. Two-way ANOVA indicated that drop height accounted for $93.8 \%$ of the variance in the data set and glove type accounted for $4.6 \%(\mathrm{P}<0.0001$ in both cases). Interaction between drop height and glove type explained only $0.4 \%$ of the variance but this effect, too, was significant at the $\mathrm{P}<$ 0.0001 level.

Tukey post-hoc comparisons between glove types at each drop height appear in Table 4. At all drop heights, the peak rate of glove deceleration was significantly less for the pneumatic gloves than for the conventional gloves. Values for the ARLI glove were significantly lower than those for the SBLI glove at drop heights of 3 metres and above. There was no consistent difference between the Std $10 \mathrm{oz}$ and Std $16 \mathrm{oz}$ gloves.

\subsection{Rebound Phase of Velocity-Time Curve}

\subsubsection{Duration of Rebound Phase}

Second-order polynomial regression equations were produced to describe the rebound component of the velocity-time curve for every drop of the different glove types. In each case, the equations were based on data points extending from the first that was unequivocally part of the rebound phase to $4 \mathrm{msec}$ after the highest observed rebound velocity. Even at the highest drop height of 5 metres, no equation was derived from less than seven data points recorded at $500 \mathrm{~Hz}$.

Overall, the curve fits were slightly less precise than those of the compressive phase, but $R^{2}$ values were still high, with means of 0.9967 (range 0.9863 - 0.9996 )

Table 4. Results of Tukey post-hoc comparisons between glove types for peak rate of negative acceleration during period between initial glove contact with force plate and attainment of zero glove velocity. Each cell shows the probability that there was no real difference between glove types. Red figures indicate a statistically significant difference and blue figures indicates absence of significance $(P>0.05)$.

\begin{tabular}{ccccccc}
\hline $\begin{array}{c}\text { Drop height } \\
(\mathrm{m})\end{array}$ & $\begin{array}{c}\text { SBLI } \\
\text { vs } \\
\text { ARLI }\end{array}$ & $\begin{array}{c}\text { SBLI } \\
\text { vs }\end{array}$ & $\begin{array}{c}\text { SBLI } \\
\text { Std } 10 \mathbf{~ o z}\end{array}$ & $\begin{array}{c}\text { ARLI } 16 \mathbf{~ o z} \\
\text { vs }\end{array}$ & $\begin{array}{c}\text { ARLI } \\
\text { std 10 oz } \\
\text { Std 16 oz }\end{array}$ & $\begin{array}{c}\text { Std 10 oz } \\
\text { vs } \\
\text { Std 16 oz }\end{array}$ \\
\hline 1.0 & 0.9240 & $<0.0001$ & $<0.0001$ & $<0.0001$ & $<0.0001$ & 0.9483 \\
1.5 & 0.7624 & $<0.0001$ & $<0.0001$ & $<0.0001$ & $<0.0001$ & 0.5243 \\
2.0 & 0.9729 & $<0.0001$ & $<0.0001$ & $<0.0001$ & $<0.0001$ & 0.9996 \\
2.5 & 0.9997 & $<0.0001$ & $<0.0001$ & $<0.0001$ & $<0.0001$ & 0.9732 \\
3.0 & 0.0047 & $<0.0001$ & $<0.0001$ & $<0.0001$ & $<0.0001$ & 0.1160 \\
3.5 & 0.0067 & $<0.0001$ & $<0.0001$ & $<0.0001$ & $<0.0001$ & 0.9934 \\
4.0 & $<0.0001$ & $<0.0001$ & $<0.0001$ & $<0.0001$ & $<0.0001$ & 0.0248 \\
4.5 & $<0.0001$ & $<0.0001$ & $<0.0001$ & $<0.0001$ & $<0.0001$ & 0.3175 \\
5.0 & $<0.0001$ & $<0.0001$ & $<0.0001$ & $<0.0001$ & $<0.0001$ & 0.0008 \\
\hline
\end{tabular}


for the SBLI glove, $0.9972(0.9883$ - 0.9996) for the ARLI glove, $0.9956(0.9872$ $0.9994)$ for the Std $10 \mathrm{oz}$ glove and 0.9955 (0.9783 - 0.9994) for the Std $16 \mathrm{oz}$ glove. Consequently, there was sound rationale for using the equations to interpolate the time corresponding to attainment of peak velocity with a resolution of $0.1 \mathrm{msec}$.

For each glove drop, the duration of the rebound phase of the time-velocity curve was calculated as the time at peak rebound velocity minus the time at zero velocity, with both these variables derived from the regression equations. Mean rebound durations for the various glove types were quite similar to those determined by subtracting time at minimum observed glove velocity from time at peak observed rebound velocity, with the observations restricted to $500 \mathrm{~Hz}$, but standard deviations were lower for 31 of the 36 data sets ( 4 gloves by 9 drop heights). The calculated durations of the rebound phase of the velocity-time curves are presented in Figure 9.

Two-way ANOVA revealed that drop height accounted for $79.8 \%$ of variance in the data, while glove type accounted for $14.4 \%$ and interaction between glove type and drop height accounted for $4.1 \%$. Therefore, only $1.7 \%$ of the variance was residual. The effects of glove type, drop height and the interaction were all statistically significant $(\mathrm{P}<0.0001)$. Results of Tukey post-hoc comparisons between glove types at each drop height are presented in Table 5 and show that rebound phase durations were always significantly longer for the pneumatic gloves than for the conventional gloves. The SBLI glove produced significantly longer rebound phase durations than the ARLI glove for drop heights up to and including 2.5 metres, but not thereafter. Differences between the Std $10 \mathrm{oz}$ and Std $16 \mathrm{oz}$ gloves were significant only at 1 and 1.5 metres.

\subsubsection{Duration of Rebound Phase versus Duration of Compressive Phase}

The rebound phase of the velocity-time curve was always of shorter duration

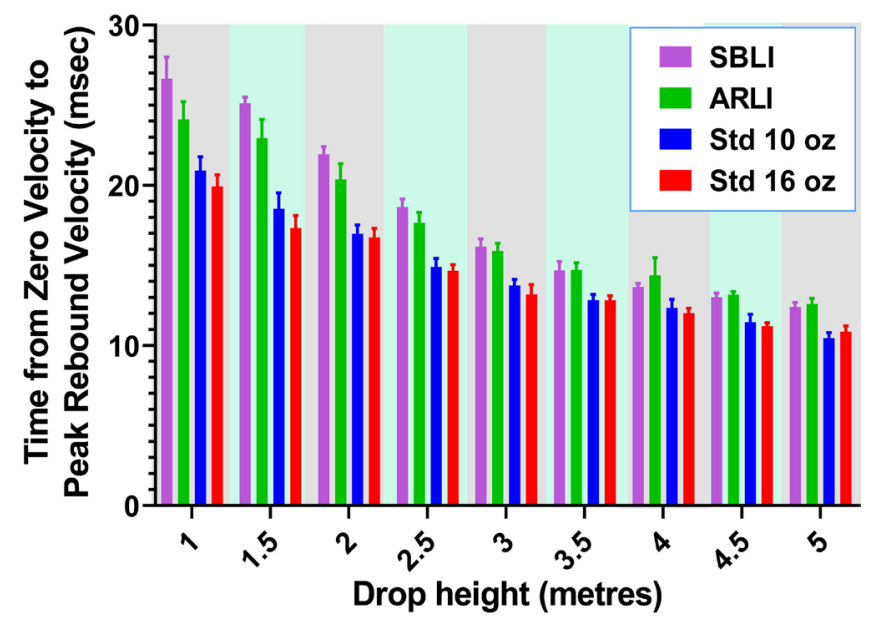

Figure 9. Duration of rebound phase of velocity-time curve for four different glove types. Each bar depicts a mean value derived from 9 - 11 glove drops, and standard deviations are also shown. Times were calculated to a resolution of $0.1 \mathrm{msec}$ using second-order polynomial regression equations based on data collected at a sampling frequency of $500 \mathrm{~Hz}$. 
Table 5. Results of Tukey post-hoc comparisons between glove types for calculated duration of rebound phase of velocity-time curve at various drop heights. Each cell shows the probability that there was no real difference between glove types. Red figures indicate a statistically significant difference and blue figures indicate absence of significance $(\mathrm{P}>0.05)$.

\begin{tabular}{|c|c|c|c|c|c|c|}
\hline $\begin{array}{l}\text { Drop height } \\
\text { (m) }\end{array}$ & $\begin{array}{c}\text { SBLI } \\
\text { vs } \\
\text { ARLI }\end{array}$ & $\begin{array}{c}\text { SBLI } \\
\text { vs } \\
\text { Std } 10 \mathrm{oz}\end{array}$ & $\begin{array}{c}\text { SBLI } \\
\text { vs } \\
\text { Std } 16 \mathrm{oz}\end{array}$ & $\begin{array}{c}\text { ARLI } \\
\text { vs } \\
\text { Std } 10 \mathrm{oz}\end{array}$ & $\begin{array}{c}\text { ARLI } \\
\text { vs } \\
\text { Std } 16 \mathrm{oz}\end{array}$ & $\begin{array}{c}\text { Std } 10 \mathrm{oz} \\
\text { vs } \\
\text { Std } 16 \mathrm{oz}\end{array}$ \\
\hline 1.0 & $<0.0001$ & $<0.0001$ & $<0.0001$ & $<0.0001$ & $<0.0001$ & 0.0033 \\
\hline 1.5 & $<0.0001$ & $<0.0001$ & $<0.0001$ & $<0.0001$ & $<0.0001$ & 0.0002 \\
\hline 2.0 & $<0.0001$ & $<0.0001$ & $<0.0001$ & $<0.0001$ & $<0.0001$ & 0.8348 \\
\hline 2.5 & 0.0033 & $<0.0001$ & $<0.0001$ & $<0.0001$ & $<0.0001$ & 0.8098 \\
\hline 3.0 & 0.7714 & $<0.0001$ & $<0.0001$ & $<0.0001$ & $<0.0001$ & 0.2187 \\
\hline 3.5 & 0.9999 & $<0.0001$ & $<0.0001$ & $<0.0001$ & $<0.0001$ & $>0.9999$ \\
\hline 4.0 & 0.0723 & 0.0005 & $<0.0001$ & $<0.0001$ & $<0.0001$ & 0.6766 \\
\hline 4.5 & 0.0946 & $<0.0001$ & $<0.0001$ & $<0.0001$ & $<0.0001$ & 0.8348 \\
\hline 5.0 & 0.9162 & $<0.0001$ & $<0.0001$ & $<0.0001$ & $<0.0001$ & 0.4774 \\
\hline
\end{tabular}

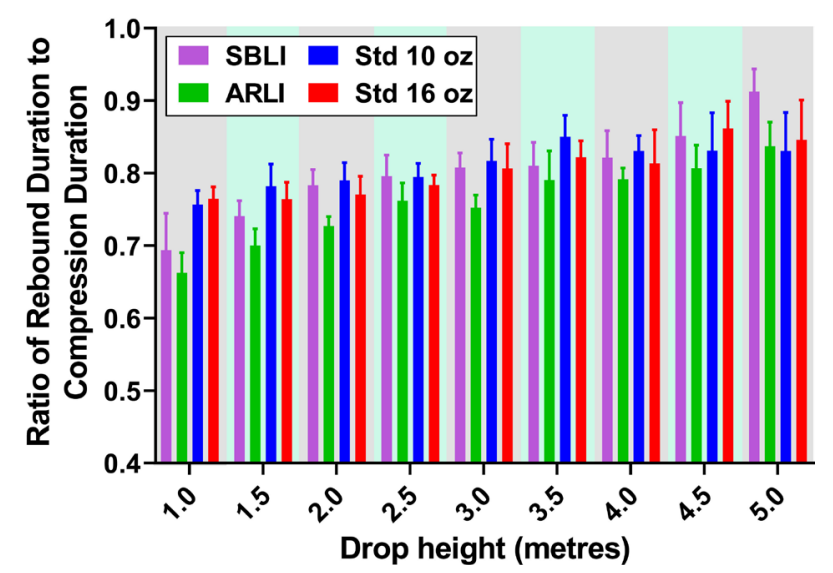

Figure 10. Proportional contribution of rebound phase duration to compression duration for four different gloves across a range of drop heights. Each bar depicts a mean value derived from 9 - 11 glove drops, and standard deviations are also shown.

than the compressive phase. Figure 10 shows that as drop height increased, so too did the ratio of rebound duration to compression duration. This indicates that the effect of drop height in reducing the duration of the rebound phase was relatively less than its effect in reducing the duration of the compressive phase. The mean ratio of rebound duration to compression duration was lower for the ARLI glove than for any of the others at every drop height except 5 metres. Two-way ANOVA showed that $51.9 \%$ of the variance in the data could be explained by drop height, $12.2 \%$ by glove type and $9.2 \%$ by interaction between glove type and drop height. All these effects were statistically significant $(\mathrm{P}<$ 0.0001 ), even though as much as $26.7 \%$ of variance in the data set was residual. Tukey post-hoc comparisons appear in Table 6. Of 22 comparisons that revealed significant differences, 16 related to the ARLI glove and reflected its tendency to 
produce lower values, especially at the lower drop heights. Values for the SBLI glove were significantly lower than those for the Std $10 \mathrm{oz}$ and Std $16 \mathrm{oz}$ gloves at the 1-metre drop height, but at a drop height at 5 metres the values for the SBLI glove were significantly higher than those for any of the other gloves. No significant differences were detected between the Std $10 \mathrm{oz}$ and Std 16 oz gloves.

\subsubsection{Peak Rebound Velocity}

Peak rebound velocities calculated from the regression equations used to characterise the rebound phase of velocity-time curves are summarised in Figure 11. Since the equations provided velocity data at intervals of $0.1 \mathrm{msec}$ the values

Table 6. Results of Tukey post-hoc comparisons between glove types for ratio of rebound phase duration to compression phase duration at various drop heights. Each cell shows the probability that there was no real difference between glove types. Red figures indicate a statistically significant difference and blue figures indicate absence of significance $(\mathrm{P}>$ $0.05)$.

\begin{tabular}{ccccccc}
\hline $\begin{array}{c}\text { Drop height } \\
(\mathrm{m})\end{array}$ & $\begin{array}{c}\text { SBLI } \\
\text { vs }\end{array}$ & $\begin{array}{c}\text { SBLI } \\
\text { vs }\end{array}$ & $\begin{array}{c}\text { SBLI } \\
\text { vs }\end{array}$ & $\begin{array}{c}\text { ARLI } \\
\text { vs }\end{array}$ & $\begin{array}{c}\text { ARLI } \\
\text { vs }\end{array}$ & $\begin{array}{c}\text { Std 10 oz } \\
\text { vs }\end{array}$ \\
\hline 1.0 & 0.1417 & $<0.0001$ & $<0.0001$ & $<0.0001$ & $<0.0001$ & 0.9349 \\
1.5 & 0.0241 & 0.0208 & 0.3462 & $<0.0001$ & $<0.0001$ & 0.6033 \\
2.0 & 0.0005 & 0.9660 & 0.8026 & $<0.0001$ & 0.0129 & 0.5176 \\
2.5 & 0.0842 & 0.9998 & 0.8271 & 0.1160 & 0.4281 & 0.8731 \\
3.0 & 0.0007 & 0.9262 & 0.9996 & $<0.0001$ & 0.0007 & 0.8820 \\
3.5 & 0.5401 & 0.0264 & 0.8362 & 0.0003 & 0.1389 & 0.1987 \\
4.0 & 0.1737 & 0.9214 & 0.9469 & 0.0317 & 0.4162 & 0.6185 \\
4.5 & 0.0134 & 0.4744 & 0.8891 & 0.3567 & 0.0012 & 0.1364 \\
5.0 & $<0.0001$ & $<0.0001$ & 0.0001 & 0.9643 & 0.9348 & 0.7099 \\
\hline
\end{tabular}

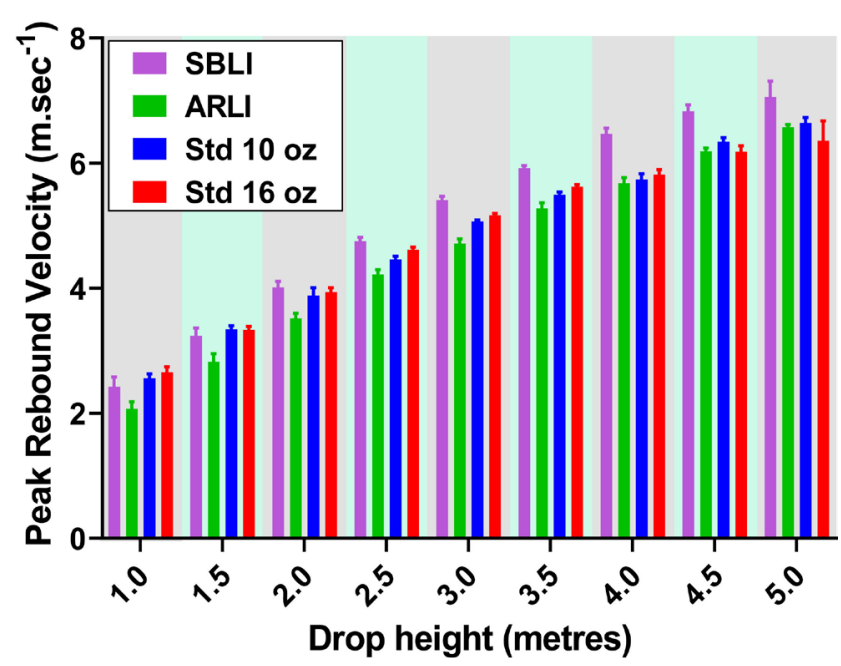

Figure 11. Peak rebound velocities of gloves as a function of glove type and drop height. Each bar depicts a mean value derived from 9 - 11 glove drops, and standard deviations are also shown. 
were slightly higher than the peak rebound velocities observed with a sampling rate of $500 \mathrm{~Hz}$, but the differences were small, averaging $0.09 \mathrm{~m} \cdot \mathrm{sec}^{-1}$ (95\% confidence interval 0.08 to $0.11 \mathrm{~m} \cdot \mathrm{sec}^{-1}$ ) for the SBLI glove, $0.08 \mathrm{~m} \cdot \mathrm{sec}^{-1}(0.07$ to 0.10 ) for the ARLI glove, $0.11 \mathrm{~m} \cdot \mathrm{sec}^{-1}$ (0.09 to 0.12$)$ for the Std $10 \mathrm{oz}$ glove and 0.11 $\mathrm{m} \cdot \mathrm{sec}^{-1}$ ( 0.10 to 0.13 ) for the Std $16 \mathrm{oz}$ glove. For every glove type, the $\mathrm{R}^{2}$ value for the relationship between values yielded by the regression equation and the peak observed values was 0.9990 or greater. It is therefore evident that our use of curve fitting procedures to increase data resolution did not compromise the fundamental integrity of the data. Figure 11 shows that at every drop height from 2 metres upwards the peak rebound velocity was highest for the SBLI glove, and at all drop heights up to 4 metres it was lowest for the ARLI glove.

\subsubsection{Coefficient of Restitution}

More instructive than peak rebound velocity alone is the kinematic coefficient of restitution, a parameter derived by dividing peak rebound velocity by the peak glove velocity attained before glove contact with the target [8] [9] [10] [11]. Coefficients of restitution are shown in Figure 12. Because we occasionally obtained peak rebound velocities that were anomalous compared with all other results within a set of 9 - 11 glove drops, we have presented Figure 12 as a series of box and whisker plots in which all data are included but the median is used in preference to the mean as the measure of central tendency and variability is indicated by both the interquartile range and the absolute range rather than the standard deviation.

The data depicted in Figure 12 were subjected to two-way ANOVA with the apparently anomalous results included. The analysis revealed that $47.6 \%$ of the variance in the data set could be explained by drop height, $30.8 \%$ by glove type, and $14.7 \%$ by interaction between drop height and glove type, with each of these effects being statistically significant $(\mathrm{P}<0.0001)$. Residual variance was $6.9 \%$ of the total variance. The results of follow-up Tukey post-hoc comparisons appear in Table 7. For drop heights up to and including 3 metres the coefficient of restitution was significantly lower for the ARLI glove than for any of the others. This suggests that in the case of the ARLI glove more of the kinetic energy of impact was converted to other energy forms. By contrast, at drops heights of 2 metres and above, the SBLI glove had a significantly higher coefficient than any of the other gloves. The coefficients for the Std $10 \mathrm{oz}$ and Std $16 \mathrm{oz}$ gloves were not consistently different from each other.

\subsubsection{Glove Acceleration during Rebound Phase and Its Relation to Acceleration during Compressive Phase}

In Figure 13, acceleration-time curves based on mean regression equation coefficients for the rebound phase of impact resulting from the dropping of gloves from a height of 3 metres are shown together with similarly derived curves relating to the compressive phase of impact. The curves indicate that during the rebound phase acceleration was positive and reached its highest point immediately following zero glove velocity. Thereafter it declined in linear fashion to 
(a) 1 metre

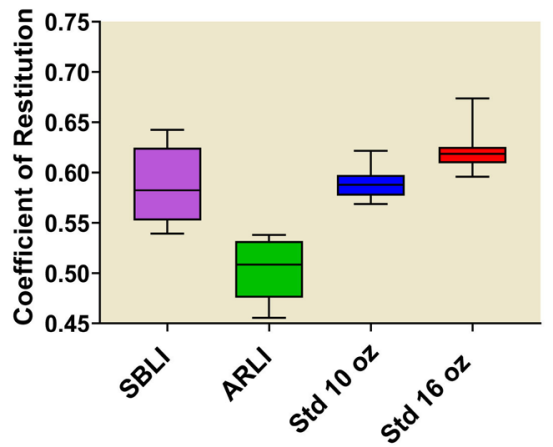

(d) 2.5 metres

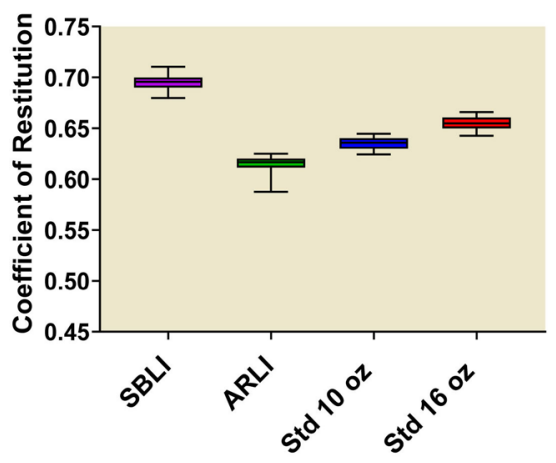

(g) 4 metres

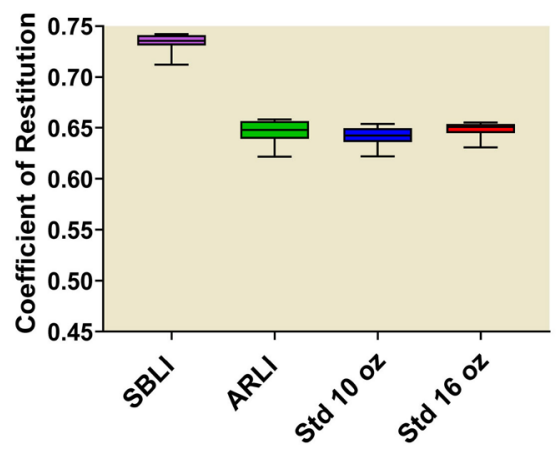

zero (with the zero point obviously corresponding to attainment of maximum rebound height of the glove).

Two other aspects of Figure 13 merit attention. Firstly, for every glove type, the peak positive acceleration during glove rebound from impact is of smaller absolute magnitude than the peak negative acceleration attained during glove compression. Secondly, the two curves for any given glove appear to be close to parallel (i.e., the curve slopes appear to be similar).

We calculated the slope of the rebound phase of the acceleration-time curve for each drop of every glove from every drop height, and compared the slope with that calculated for the glove compression phase of the same drop. The (b) 1.5 metres

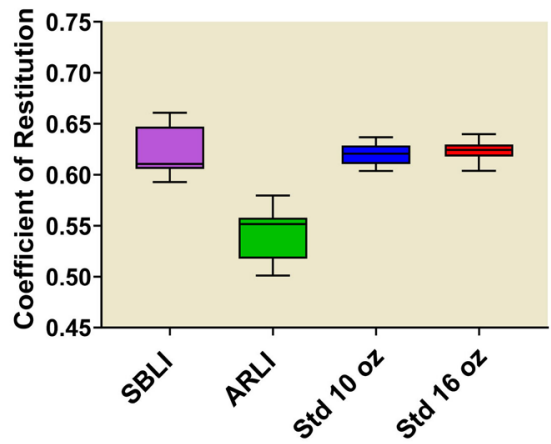

(e) 3 metres

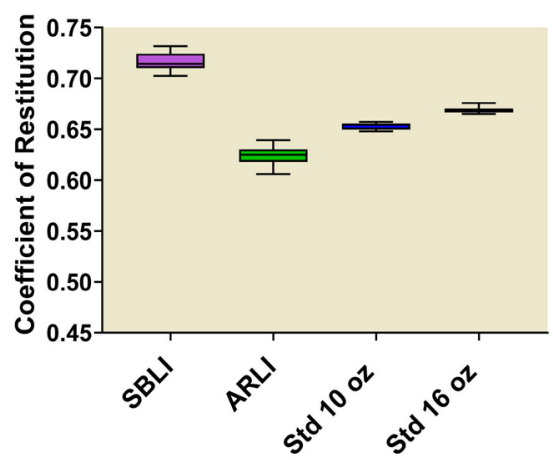

(h) 4.5 metres

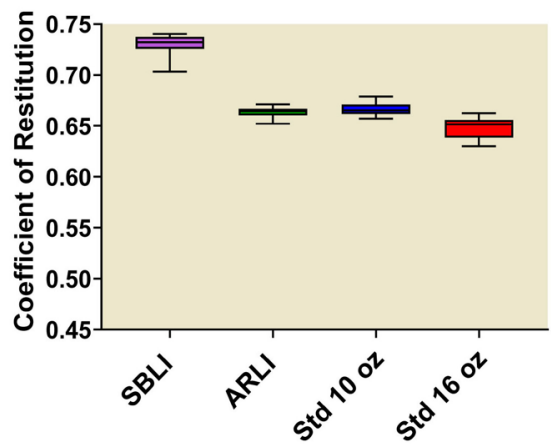

(c) 2 metres

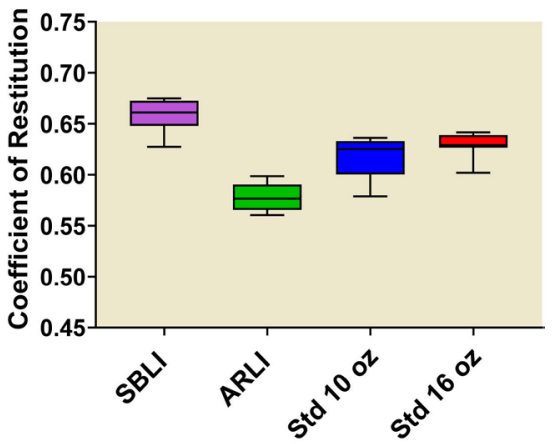

(f) 3.5 metres

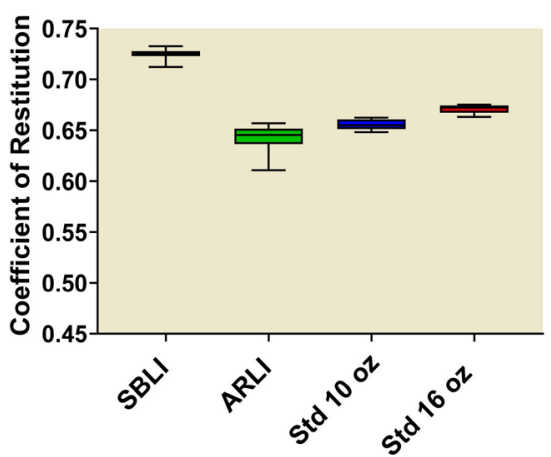

(i) 5 metres

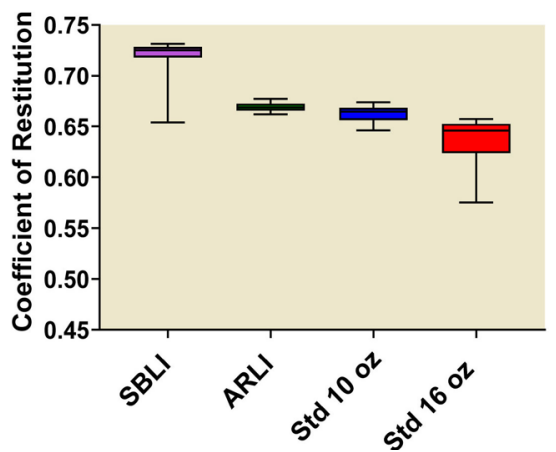

Figure 12. Coefficients of restitution for different glove types at various drop heights. In each case, the shaded box indicates the $25^{\text {th }}-75^{\text {th }}$ percentile range, the bar within the box indicates the median value, and the lines extending above and below the box show the absolute range of the scores. 
Table 7. Results of Tukey post-hoc comparisons between glove types for coefficient of restitution at various drop heights. Each cell shows the probability that there was no real difference between glove types. Red figures indicate a statistically significant difference and blue figures indicate absence of significance $(\mathrm{P}>0.05)$.

\begin{tabular}{|c|c|c|c|c|c|c|}
\hline $\begin{array}{l}\text { Drop height } \\
\text { (m) }\end{array}$ & $\begin{array}{l}\text { SBLI } \\
\text { vs } \\
\text { ARLI }\end{array}$ & $\begin{array}{c}\text { SBLI } \\
\text { vs } \\
\text { Std } 10 \mathrm{oz}\end{array}$ & $\begin{array}{c}\text { SBLI } \\
\text { vs } \\
\text { Std } 16 \mathrm{oz}\end{array}$ & $\begin{array}{c}\text { ARLI } \\
\text { vs } \\
\text { Std } 10 \mathrm{oz}\end{array}$ & $\begin{array}{c}\text { ARLI } \\
\text { vs } \\
\text { Std } 16 \mathrm{oz}\end{array}$ & $\begin{array}{c}\text { Std } 10 \mathrm{oz} \\
\text { vs } \\
\text { Std } 16 \mathrm{oz}\end{array}$ \\
\hline 1.0 & $<0.0001$ & 0.9641 & $<0.0001$ & $<0.0001$ & $<0.0001$ & $<0.0001$ \\
\hline 1.5 & $<0.0001$ & 0.9909 & 0.9918 & $<0.0001$ & $<0.0001$ & 0.9320 \\
\hline 2.0 & $<0.0001$ & $<0.0001$ & $<0.0001$ & $<0.0001$ & $<0.0001$ & 0.3817 \\
\hline 2.5 & $<0.0001$ & $<0.0001$ & $<0.0001$ & 0.0137 & $<0.0001$ & 0.0298 \\
\hline 3.0 & $<0.0001$ & $<0.0001$ & $<0.0001$ & $<0.0001$ & $<0.0001$ & 0.1113 \\
\hline 3.5 & $<0.0001$ & $<0.0001$ & $<0.0001$ & 0.2311 & 0.0003 & 0.1165 \\
\hline 4.0 & $<0.0001$ & $<0.0001$ & $<0.0001$ & 0.9217 & 0.9837 & 0.7529 \\
\hline 4.5 & $<0.0001$ & $<0.0001$ & $<0.0001$ & 0.9724 & 0.0491 & 0.1110 \\
\hline 5.0 & $<0.0001$ & $<0.0001$ & $<0.0001$ & 0.7710 & $<0.0001$ & 0.0002 \\
\hline
\end{tabular}

\section{3 metres}

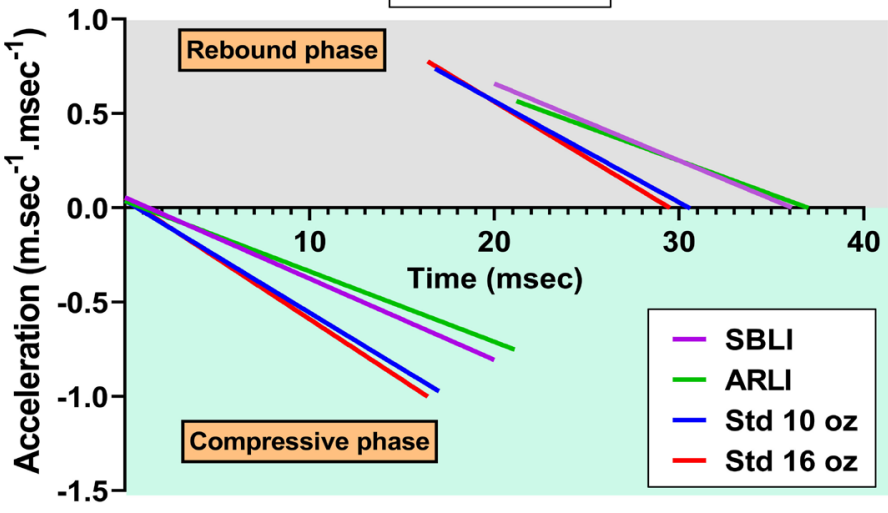

Figure 13. Mean acceleration profiles for different glove types during the glove compression and glove rebound phases of impact produced through dropping of gloves on to a force plate from a height of 3 metres.

overall results are summarised in Figure 14. For the SBLI and ARLI gloves, mean slopes for the compressive and rebound phases were almost identical up to and including a drop height of 2.5 metres, after which some separation began to occur. An analogous pattern was evident for the Std $10 \mathrm{oz}$ and Std $16 \mathrm{oz}$ gloves, but separation of the curves commenced slightly earlier. The degree of separation was least for the ARLI glove. Two-way ANOVA showed that for the ARLI glove a total of only $1.4 \%$ of the variance in the data set could be explained by either impact phase and/or interaction between impact phase and drop height, while the corresponding percentages for the SBLI, Std $10 \mathrm{oz}$ and Std $16 \mathrm{oz}$ gloves were $3.6 \%, 2.0 \%$ and $2.5 \%$ respectively. The results of multiple comparison tests are presented in Table 8 and reveal that for the SBLI, Std $10 \mathrm{oz}$ and $16 \mathrm{oz}$ gloves, the acceleration-time slopes for the compressive and rebound phases were not 

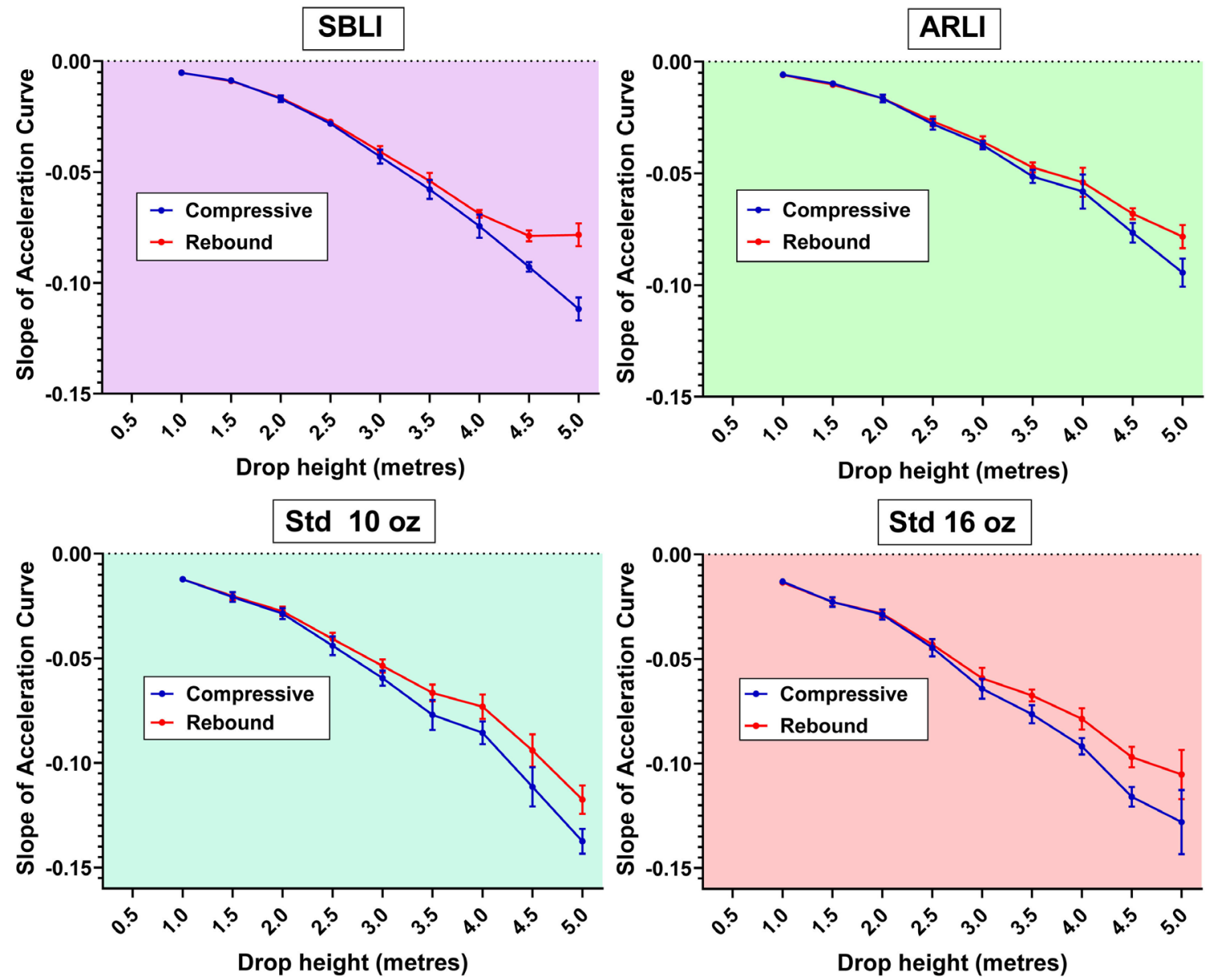

Figure 14. Comparison of slopes of acceleration-time curves between glove compression and glove rebound phases of impact for four different gloves across a range of drop heights. Each point represents a mean for 9 - 11 glove drops. Standard deviations are also shown but in some cases are so small as to be imperceptible

Table 8. Results of multiple comparisons between slopes of acceleration-time curves for compressive and rebound phases of impacts generated by dropping gloves on to a force plate from various heights. Slope comparisons are provided for each of four different glove types. Each cell shows the probability that there was no real difference between the two slopes. Red figures indicate a statistically significant difference and blue figures indicate absence of significance $(\mathrm{P}>0.05)$.

\begin{tabular}{ccccc}
\hline Drop height $(\mathrm{m})$ & SBLI & ARLI & Std 10 oz & Std 16 oz \\
\hline $1.0 \mathrm{~m}$ & $>0.9999$ & $>0.9999$ & $>0.9999$ & $>0.9999$ \\
$1.5 \mathrm{~m}$ & $>0.9999$ & $>0.9999$ & $>0.9999$ & $>0.9999$ \\
$2.0 \mathrm{~m}$ & $>0.9999$ & $>0.9999$ & 0.9999 & $>0.9999$ \\
$2.5 \mathrm{~m}$ & 0.9986 & 0.9956 & 0.7807 & 0.9991 \\
$3.0 \mathrm{~m}$ & 0.6175 & 0.9714 & 0.0742 & 0.3831 \\
$3.5 \mathrm{~m}$ & 0.0325 & 0.1548 & $<0.0001$ & 0.0049 \\
$4.0 \mathrm{~m}$ & 0.0005 & 0.0986 & $<0.0001$ & $<0.0001$ \\
$4.5 \mathrm{~m}$ & $<0.0001$ & $<0.0001$ & $<0.0001$ & $<0.0001$ \\
$5.0 \mathrm{~m}$ & $<0.0001$ & $<0.0001$ & $<0.0001$ & $<0.0001$ \\
\hline
\end{tabular}


significantly different until a drop height of 3.5 metres and were then significantly different also at drop heights of 4, 4.5 and 5 metres. In the case of the ARLI glove, significant difference was detected only at 4.5 and 5 metres.

In Figure 15, peak positive glove acceleration during the rebound phase is shown for each glove type and drop height, and compared with the peak negative acceleration during the compressive phase. Based on the linear nature of the acceleration-time curves, it can be surmised that peak negative acceleration in the compressive phase occurred immediately before the point of zero glove velocity whereas peak positive acceleration occurred immediately after that point. A clear revelation of Figure 15 is that the positive acceleration graph is almost a mirror image of the negative acceleration graph, except that for any combination of glove type and drop height, the magnitude of peak positive acceleration during rebound is lower than the magnitude of peak negative acceleration during glove compression. Two-way ANOVA showed that $93.5 \%$ of the variance in peak rebound acceleration could be explained as a function of drop height, 4.7\% could be attributed to glove type, and $0.8 \%$ was explicable in terms of the interaction between glove type and drop height. These results closely resembled
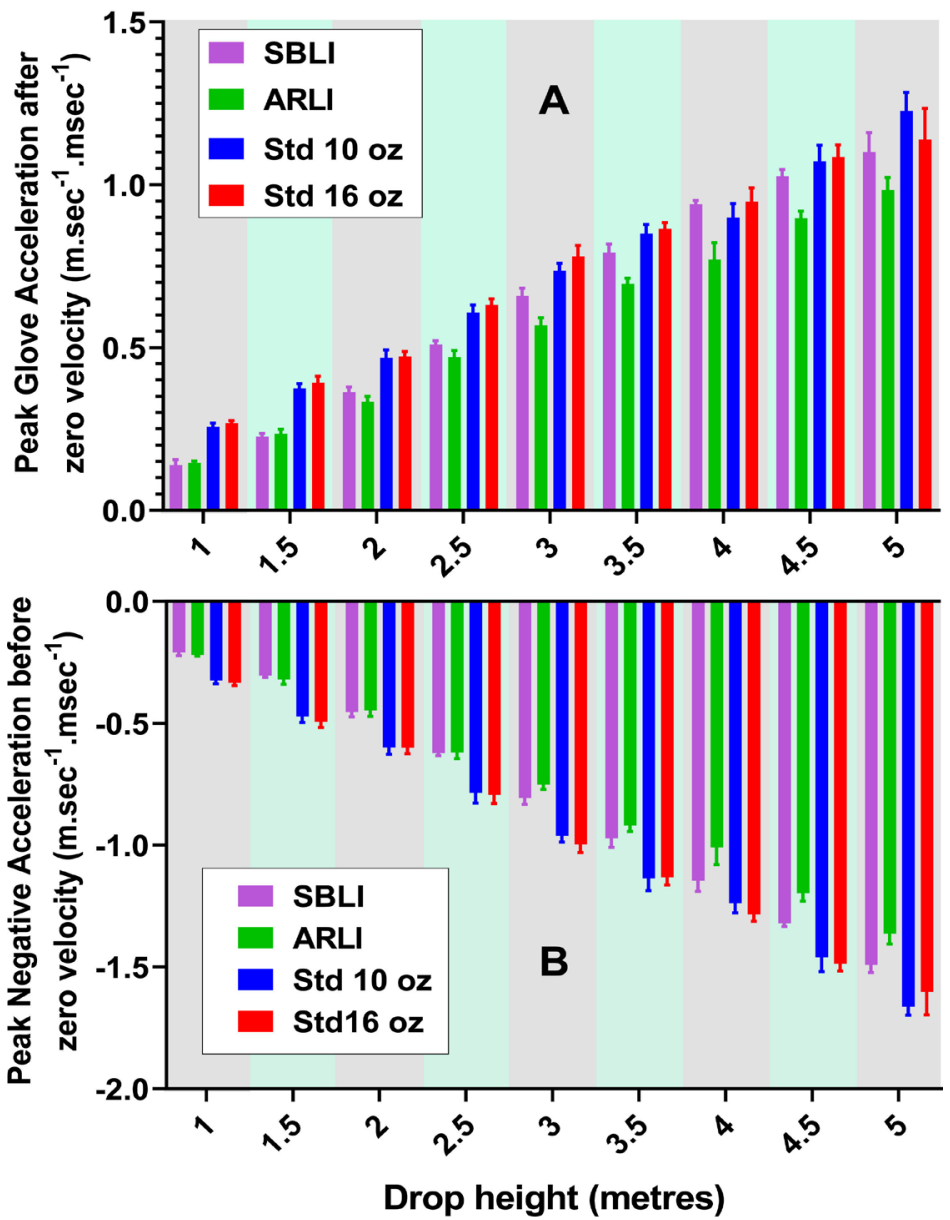

Figure 15. Peak positive acceleration during the rebound phase of glove impact (Panel A) compared with peak negative acceleration during the compressive phase (Panel B). Each column depicts a mean value and standard deviations are also shown. 
those reported above for peak negative acceleration during the compressive phase of glove impact. Not surprisingly, Tukey post-hoc comparisons of differences in peak positive rebound acceleration between gloves at each of the different drop heights (see Table 9) also produced findings very similar to those obtained for peak negative acceleration during glove compression (Table 4).

It may not be immediately obvious from Figure 15 that there was some variation between gloves in terms of the effects of drop height on change in peak acceleration. Figure 16 is based on the same data sets as Figure 15 but shows the linear regression relationship between drop height and peak positive and negative acceleration readings for each glove type. For the compressive phase of impact, the increase in peak negative acceleration per increment in drop height was less for the ARLI glove than any of the others $(\mathrm{P}<0.004$ in each case), while there was no significant difference between the SBLI, Std $10 \mathrm{oz}$ and Std $16 \mathrm{oz}$ gloves $(\mathrm{P}>0.05)$. For the rebound phase, on the other hand, it was the SBLI glove that tended to differ from the others, showing greater increase in peak positive acceleration per increment in drop height. The SBLI glove differed significantly from the ARLI and Std 16 oz gloves $(\mathrm{P}<0.02$ in each case). There were no other significant differences between glove types, although the mean increase in peak positive acceleration per increment in drop height was lowest for the ARLI glove.

We thought it worthwhile to closely examine the period of transition from the compressive phase of glove impact to the rebound phase. Since glove deceleration during compression occurred in the instant before zero glove velocity and peak acceleration during rebound occurred in the instant immediately after zero velocity, we explored the relationship between these two parameters. Peak positive acceleration and peak negative acceleration were summed, which effectively

Table 9. Results of Tukey post-hoc comparisons between glove types for peak rate of positive acceleration during glove rebound. Each cell shows the probability that there was no real difference between glove types. Red figures indicate a statistically significant difference and blue figures indicate absence of significance $(P>0.05)$.

\begin{tabular}{|c|c|c|c|c|c|c|}
\hline $\begin{array}{c}\text { Drop height } \\
\text { (m) }\end{array}$ & $\begin{array}{l}\text { SBLI } \\
\text { vs } \\
\text { ARLI }\end{array}$ & $\begin{array}{c}\text { SBLI } \\
\text { vs } \\
\text { Std } 10 \mathrm{oz}\end{array}$ & $\begin{array}{c}\text { SBLI } \\
\text { vs } \\
\text { Std } 16 \mathrm{oz}\end{array}$ & $\begin{array}{c}\text { ARLI } \\
\text { vs } \\
\text { Std } 10 \mathrm{oz}\end{array}$ & $\begin{array}{c}\text { ARLI } \\
\text { vs } \\
\text { Std } 16 \mathrm{oz}\end{array}$ & $\begin{array}{c}\text { Std } 10 \mathrm{oz} \\
\text { vs } \\
\text { Std } 16 \mathrm{oz}\end{array}$ \\
\hline 1.0 & 0.9655 & $<0.0001$ & $<0.0001$ & $<0.0001$ & $<0.0001$ & 0.8675 \\
\hline 1.5 & 0.9588 & $<0.0001$ & $<0.0001$ & $<0.0001$ & $<0.0001$ & 0.6152 \\
\hline 2.0 & 0.2099 & $<0.0001$ & $<0.0001$ & $<0.0001$ & $<0.0001$ & 0.9880 \\
\hline 2.5 & 0.0375 & $<0.0001$ & $<0.0001$ & $<0.0001$ & $<0.0001$ & 0.3890 \\
\hline 3.0 & $<0.0001$ & $<0.0001$ & $<0.0001$ & $<0.0001$ & $<0.0001$ & 0.0154 \\
\hline 3.5 & $<0.0067$ & 0.0004 & $<0.0001$ & $<0.0001$ & $<0.0001$ & 0.7823 \\
\hline 4.0 & $<0.0001$ & 0.0320 & 0.9577 & $<0.0001$ & $<0.0001$ & 0.0051 \\
\hline 4.5 & $<0.0001$ & 0.0080 & 0.0004 & $<0.0001$ & $<0.0001$ & 0.8318 \\
\hline 5.0 & $<0.0001$ & $<0.0001$ & 0.0455 & $<0.0001$ & $<0.0001$ & $<0.0001$ \\
\hline
\end{tabular}




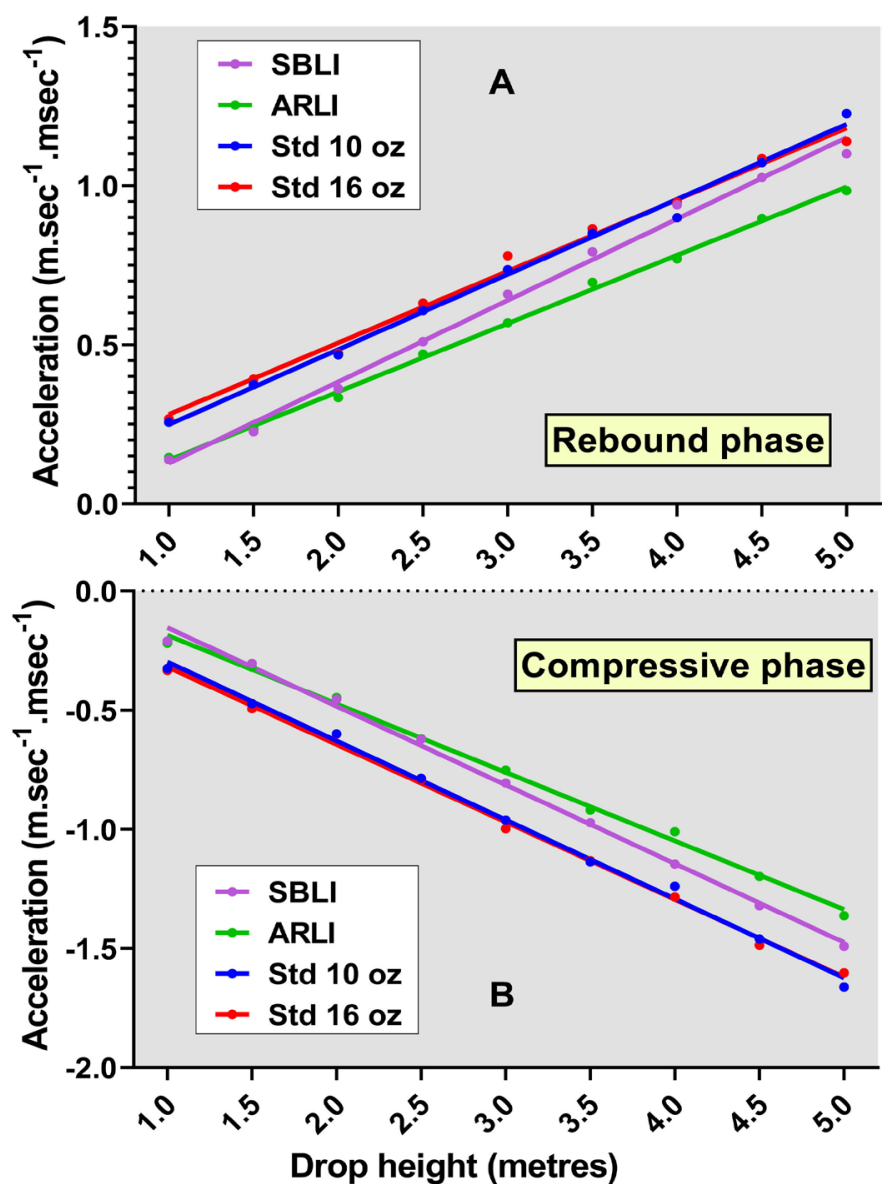

Figure 16. Linear regression relationships between drop height and peak positive acceleration during the rebound phase of glove impact (Panel A) and peak negative acceleration during the compressive phase of impact (Panel B). Relationships are shown for each glove type. The data points depicted by the circles on the graph are mean values from which linear regression equations were calculated. $\mathrm{R}^{2}$ values always exceeded 0.9910 for curves presented in Panel A and 0.9960 for curves presented in Panel B.

yielded the difference in their absolute values, and the result was then divided by the peak negative acceleration. For example, for the SBLI glove at drop height of 1 metre the calculated acceleration was $-0.1974 \mathrm{~m} \cdot \mathrm{sec}^{-1} \cdot \mathrm{msec}^{-1}$ at the end of compression and $0.1273 \mathrm{~m} \cdot \mathrm{sec}^{-1} \cdot \mathrm{msec}^{-1}$ at the beginning of rebound. The sum of these values is $-0.0701 \mathrm{~m} \cdot \mathrm{sec}^{-1} \cdot \mathrm{msec}^{-1}$ and dividing this by the value obtained at the end of compression $\left(-0.1974 \mathrm{~m} \cdot \mathrm{sec}^{-1} \cdot \mathrm{msec}^{-1}\right)$ yields an index of 0.3551 . We considered that the index obtained in this way might reflect the energy dissipation associated with transition. The results are shown in Figure 17. Two-way ANOVA revealed that $22.9 \%$ of the variance in the index could be explained by drop height, $10.1 \%$ by glove type and $43.9 \%$ by interaction between glove type and drop height, with all these effects being statistically significant $(\mathrm{P}<0.0001)$. Tukey post-hoc comparisons are presented in Table 10. Even just a quick glance at that Table reveals that the difference between gloves changed markedly as a function of drop height-hence the high percentage contribution of interaction to the overall variance in the data set. In view of the large interaction effect, we 


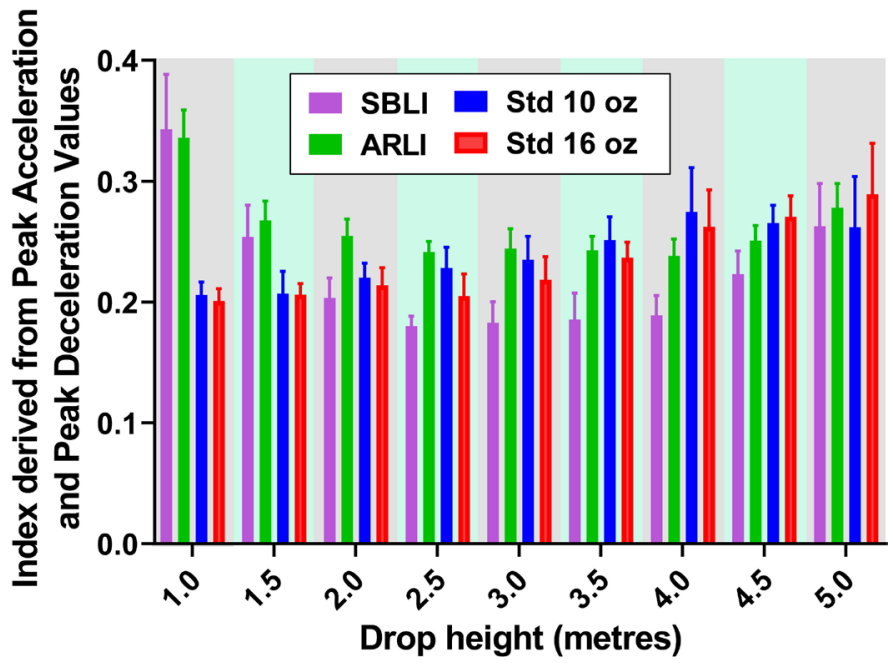

Figure 17. Effect of glove type and drop height on an index calculated with the aim of quantifying energy transfer occurring during transition from glove compression to glove rebound. The index was calculated as follows: (Peak Positive Acceleration + Peak Negative Acceleration)/Peak Negative Acceleration.

Table 10. Results of Tukey post-hoc comparisons between glove types for an index expressing the relationship between peak rate of positive acceleration during glove rebound and peak rate of negative acceleration (deceleration) during compression. Each cell shows the probability that there was no real difference between glove types. Red figures indicate a statistically significant difference and blue figures indicate absence of significance $(\mathrm{P}>$ $0.05)$.

\begin{tabular}{|c|c|c|c|c|c|c|}
\hline $\begin{array}{l}\text { Drop height } \\
\text { (m) }\end{array}$ & $\begin{array}{c}\text { SBLI } \\
\text { vs } \\
\text { ARLI }\end{array}$ & $\begin{array}{c}\text { SBLI } \\
\text { vs } \\
\text { Std } 10 \mathrm{oz}\end{array}$ & $\begin{array}{c}\text { SBLI } \\
\text { vs } \\
\text { Std } 16 \mathrm{oz}\end{array}$ & $\begin{array}{c}\text { ARLI } \\
\text { vs } \\
\text { Std } 10 \mathrm{oz}\end{array}$ & $\begin{array}{c}\text { ARLI } \\
\text { vs } \\
\text { Std } 16 \mathrm{oz}\end{array}$ & $\begin{array}{c}\text { Std } 10 \mathrm{oz} \\
\text { vs } \\
\text { Std } 16 \mathrm{oz}\end{array}$ \\
\hline 1.0 & 0.9068 & $<0.0001$ & $<0.0001$ & $<0.0001$ & $<0.0001$ & 0.9557 \\
\hline 1.5 & 0.5357 & $<0.0001$ & $<0.0001$ & $<0.0001$ & $<0.0001$ & 0.9998 \\
\hline 2.0 & $<0.0001$ & 0.3157 & 0.7079 & 0.0025 & 0.0002 & 0.9161 \\
\hline 2.5 & $<0.0001$ & $<0.0001$ & 0.0525 & 0.5471 & 0.0013 & 0.0972 \\
\hline 3.0 & $<0.0001$ & $<0.0001$ & 0.0023 & 0.7694 & 0.0360 & 0.3251 \\
\hline 3.5 & $<0.0001$ & $<0.0001$ & $<0.0001$ & 0.8326 & 0.9278 & 0.4393 \\
\hline 4.0 & $<0.0001$ & $<0.0001$ & $<0.0001$ & 0.0013 & 0.0653 & 0.5899 \\
\hline 4.5 & 0.0295 & $<0.0001$ & $<0.0001$ & 0.4597 & 0.1976 & 0.9520 \\
\hline 5.0 & 0.4174 & 0.9999 & 0.3524 & $<0.0001$ & 0.6663 & 0.0287 \\
\hline
\end{tabular}

compared the different glove types in terms of the pattern of change in the relationship between the calculated index and drop height. For both conventional gloves, the relationship showed a high degree of linearity, with the index increasing as drop height increased, although in the case of the Std $10 \mathrm{oz}$ glove it appeared to reach a plateau at a drop height of 4 metres. For both pneumatic gloves, the index initially decreased as a function of drop height, before stabilising and finally increasing. 


\subsection{Relationship of Velocity Measurements to Force Measurements}

\subsubsection{Temporal Relationships}

In Figure 18, measured glove velocities and impact forces following contact with the force plate are plotted on the same time scale. While the data relate to a drop height of 3 metres, they show a trend that was observed at all drop heights, namely that the peak force occurred in much closer temporal proximity to minimum glove velocity for the pneumatic gloves than for the Std $10 \mathrm{oz}$ and Std $16 \mathrm{oz}$ gloves.

The temporal relationship between peak impact force and time to zero glove velocity is shown for all glove types and drop heights in Figure 19. At drop heights of 2.5 metres and above, the mean time difference for both pneumatic gloves was close to zero, while for the conventional gloves peak force always preceded zero glove velocity by at least $4 \mathrm{msec}$. Two-way ANOVA revealed that drop height, glove type and interaction between drop height and glove type accounted for $49.9 \%, 38.3 \%$ and $4.8 \%$ respectively of the variance in the data set, with all these influences being statistically significant $(\mathrm{P}<0.0001)$. The results of subsequent Tukey post-hoc comparisons are presented in Table 11. The intervals

SBLI - 3 metres

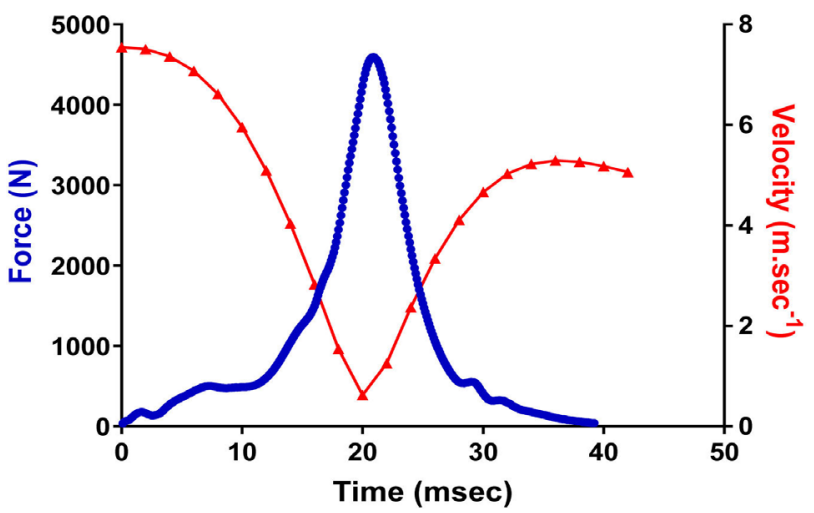

Std 10 oz - 3 metres

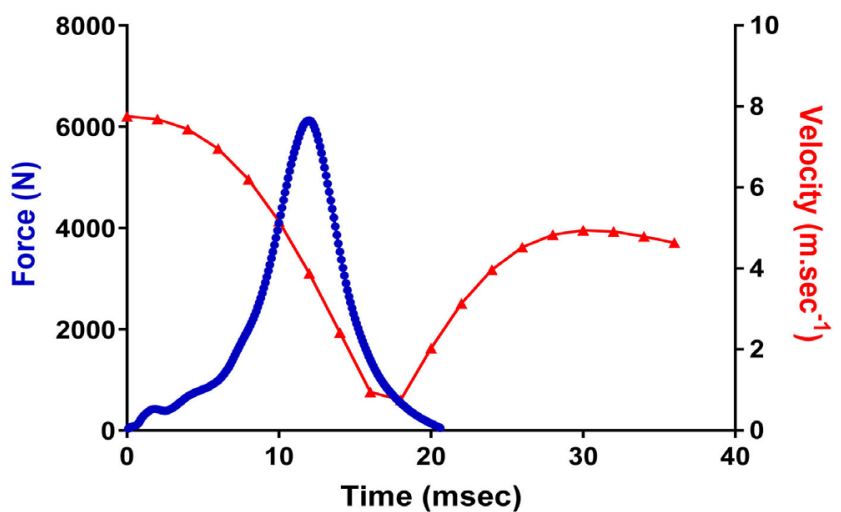

ARLI - 3 metres

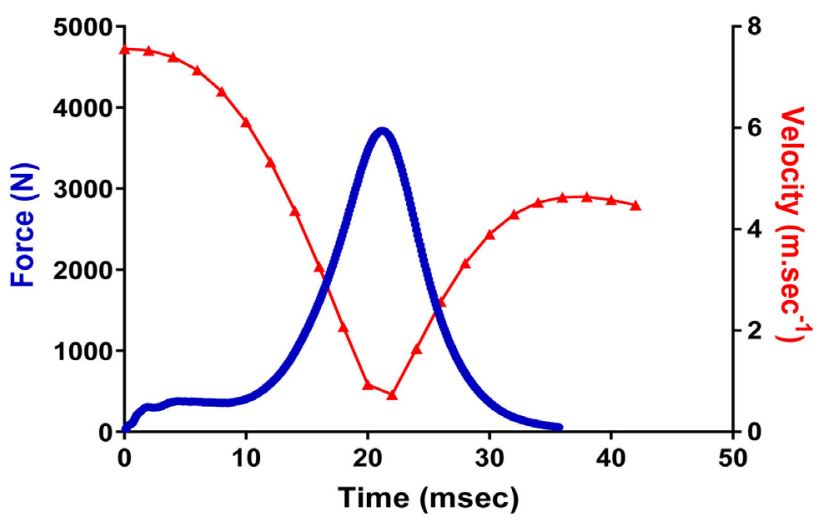

Std 16 oz - 3 metres

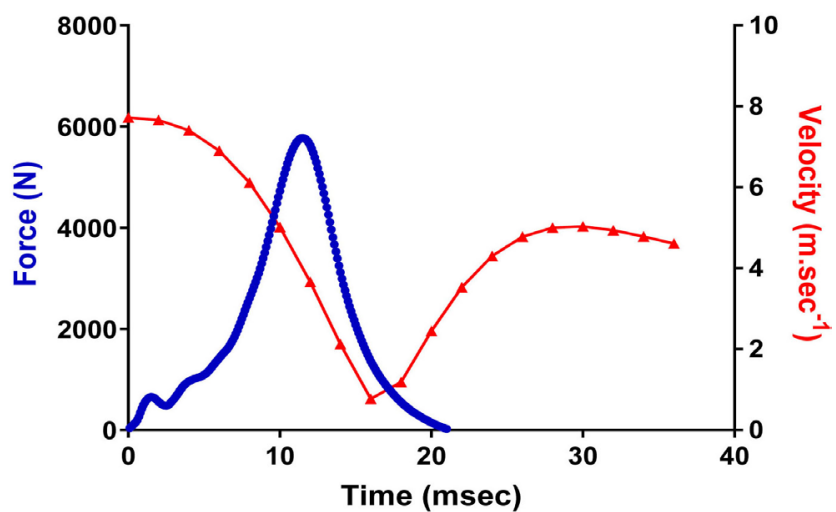

Figure 18. Average force-time and velocity-time curves for four different gloves dropped on to a force plate from a height of 3 metres. Force measures were obtained at a sampling rate of $10,000 \mathrm{~Hz}$ while velocity was measured using cameras operating at 500 frames per second. 


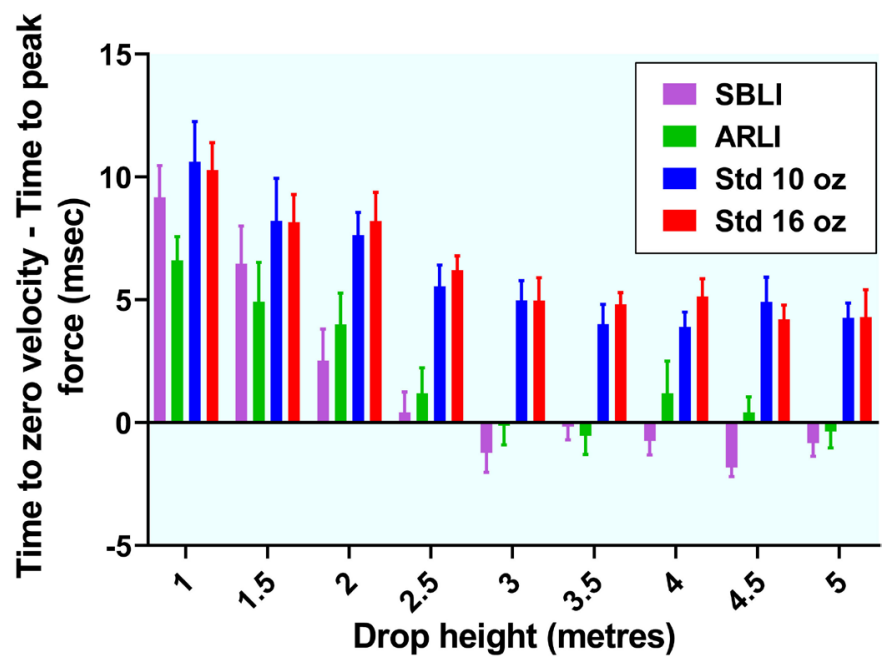

Figure 19. Effect of glove type and drop height on the time interval between occurrence of zero glove velocity and occurrence of peak impact force. Force measures were obtained at a sampling rate of $10,000 \mathrm{~Hz}$. Velocity was measured using cameras operating at 500 frames per second, with second-order polynomial regression equations then fitted to the data and used to interpolate velocity data at $10,000 \mathrm{~Hz}$.

Table 11. Results of Tukey post-hoc comparisons between glove types for time interval between occurrence of peak impact force and calculated zero glove velocity at various drop heights. Each cell shows the probability that there was no real difference between glove types. Red indicates a statistically significant difference and blue indicates absence of significance $(\mathrm{P}>0.05)$.

\begin{tabular}{|c|c|c|c|c|c|c|}
\hline $\begin{array}{l}\text { Drop height } \\
\qquad(\mathrm{m})\end{array}$ & $\begin{array}{l}\text { SBLI } \\
\text { vs } \\
\text { ARLI }\end{array}$ & $\begin{array}{c}\text { SBLI } \\
\text { vs } \\
\text { Std } 10 \mathrm{oz}\end{array}$ & $\begin{array}{c}\text { SBLI } \\
\text { vs } \\
\text { Std } 16 \mathrm{oz}\end{array}$ & $\begin{array}{c}\text { ARLI } \\
\text { vs } \\
\text { Std } 10 \mathrm{oz}\end{array}$ & $\begin{array}{c}\text { ARLI } \\
\text { vs } \\
\text { Std } 16 \mathrm{oz}\end{array}$ & $\begin{array}{c}\text { Std } 10 \mathrm{oz} \\
\text { vs } \\
\text { Std } 16 \mathrm{oz}\end{array}$ \\
\hline 1.0 & $<0.0001$ & 0.0070 & 0.0638 & $<0.0001$ & $<0.0001$ & 0.8715 \\
\hline 1.5 & 0.0046 & 0.0009 & 0.0015 & $<0.0001$ & 0.0002 & 0.9991 \\
\hline 2.0 & 0.0056 & $<0.0001$ & $<0.0001$ & $<0.0001$ & $<0.0001$ & 0.5781 \\
\hline 2.5 & 0.3121 & $<0.0001$ & $<0.0001$ & $<0.0001$ & $<0.0001$ & 0.4816 \\
\hline 3.0 & 0.0685 & $<0.0001$ & $<0.0001$ & $<0.0001$ & $<0.0001$ & $>0.9999$ \\
\hline 3.5 & 0.8545 & $<0.0001$ & $<0.0001$ & $<0.0001$ & $<0.0001$ & 0.2787 \\
\hline 4.0 & 0.0002 & $<0.0001$ & 0.0003 & $<0.0001$ & $<0.0001$ & 0.0294 \\
\hline 4.5 & $<0.0001$ & $<0.0001$ & $<0.0001$ & $<0.0001$ & $<0.0001$ & 0.3852 \\
\hline 5.0 & 0.7433 & $<0.0001$ & $<0.0001$ & $<0.0001$ & $<0.0001$ & 0.9997 \\
\hline
\end{tabular}

between time to peak force and time to zero glove velocity for the ARLI glove were significantly less than those for the Std $10 \mathrm{oz}$ and Std $16 \mathrm{oz}$ gloves at all drop heights. The same was true for the SBLI glove with the sole exception of its comparison with the result for the Std 16 oz glove at the 1-metre drop height, where the difference almost reached statistical significance. The mean value for the ARLI glove was significantly less than that for the SBLI glove at drop heights of 1 and 1.5 metres, but thereafter the ARLI produced slightly higher mean values, with the differences sometimes statistically significant. Results for Std $10 \mathrm{oz}$ 
and Std $16 \mathrm{oz}$ gloves were generally quite similar, with a significant difference between these gloves being registered only at a drop height of 4 metres. Overall, the shorter intervals observed for the pneumatic gloves relative to the conventional gloves were due to an effect in delaying the time to peak force more than the time to zero glove velocity. Averaged across all drop heights, the SBLI glove extended the time to peak force by $75.3 \%$ compared to that for the Std $10 \mathrm{oz}$ glove but extended the time to occurrence of zero glove velocity by only $23.2 \%$. Corresponding figures for the ARLI glove were $73.5 \%$ and $25.7 \%$.

Figure 20 shows the time between the end of force plate contact and the attainment of peak rebound glove velocity for the various glove types. For the Std $10 \mathrm{oz}$ and Std $16 \mathrm{oz}$ gloves, peak rebound velocity always occurred several milliseconds after cessation of glove contact with the force plate. For the ARLI glove there was much closer temporal correspondence between the two events. In the case of the SBLI glove at drop heights of 2 metres and above, peak rebound velocity was observed before the end of force plate contact. Two-way ANOVA revealed that $12.1 \%$ of the variance in the data set could be explained by drop height, $81.1 \%$ by glove type and $2.1 \%$ by interaction between glove type and drop height, with all these effects statistically significant $(\mathrm{P}<0.0001)$. Tukey post-hoc comparisons yielded the results presented in Table 12. The SBLI and ARLI gloves were statistically different from the Std $10 \mathrm{oz}$ and Std $16 \mathrm{oz}$ gloves at all drop heights, and also statistically different from each other at every drop height except 1 metre. Significant differences between the Std $10 \mathrm{oz}$ and Std $16 \mathrm{oz}$ gloves were seen only at the 1.5 and 2-metre drop heights.

\subsubsection{Relationship of Peak Glove Deceleration during Compressive Phase to Peak Impact Force}

We sought to determine the extent to which the effects of the pneumatic gloves

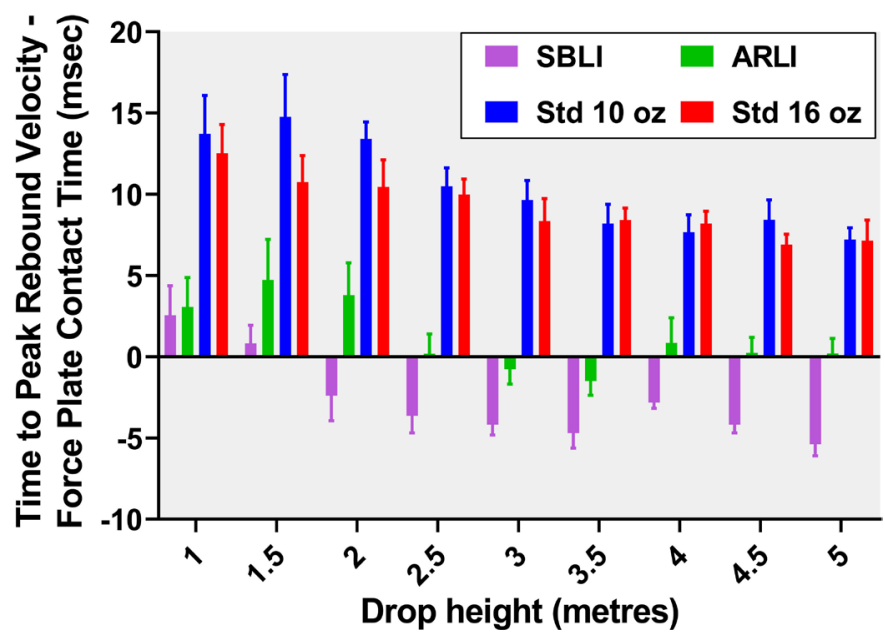

Figure 20. Effect of glove type and drop height on the time interval between end of glove contact with force plate and occurrence of peak rebound velocity of the glove. Force measures were obtained at a sampling rate of $10,000 \mathrm{~Hz}$. Velocity was measured using cameras operating at 500 frames per second, with second-order polynomial regression equations then fitted to the data and used to interpolate velocity data at $10,000 \mathrm{~Hz}$. 
in changing whole-glove deceleration (as derived from data provided by the Vicon Motion Capture System) during the compressive phase of impact was associated with their ability to reduce peak impact forces measured by the force plate. Figure 21 shows that for each glove type there was a strong linear relationship between peak negative acceleration during the compressive phase and the peak recorded impact force. $\mathrm{R}^{2}$ values were $0.9568,0.9740,0.9646$ and 0.9603 for the SBLI, ARLI, Std $10 \mathrm{oz}$ and Std $16 \mathrm{oz}$ gloves respectively. This accorded with expectations based on Newton's second law of motion. As shown in Table 13, however, the slope of the relationship was significantly less steep for the ARLI glove than for any of the other gloves. By contrast, the slope for the SBLI glove

Table 12. Results of Tukey post-hoc comparisons between glove types for time interval between end of force plate contact and occurrence of peak rebound velocity of the glove. Each cell shows the probability that there was no real difference between glove types. Red figures indicate a statistically significant difference and blue figures indicate absence of significance $(\mathrm{P}>0.05)$.

\begin{tabular}{|c|c|c|c|c|c|c|}
\hline $\begin{array}{l}\text { Drop height } \\
\text { (m) }\end{array}$ & $\begin{array}{l}\text { SBLI } \\
\text { vs } \\
\text { ARLI }\end{array}$ & $\begin{array}{c}\text { SBLI } \\
\text { vs } \\
\text { Std } 10 \mathrm{oz}\end{array}$ & $\begin{array}{c}\text { SBLI } \\
\text { vs } \\
\text { Std } 16 \mathrm{oz}\end{array}$ & $\begin{array}{c}\text { ARLI } \\
\text { vs } \\
\text { Std } 10 \mathrm{oz}\end{array}$ & $\begin{array}{c}\text { ARLI } \\
\text { vs } \\
\text { Std } 16 \mathrm{oz}\end{array}$ & $\begin{array}{c}\text { Std } 10 \mathrm{oz} \\
\text { vs } \\
\text { Std } 16 \mathrm{oz}\end{array}$ \\
\hline 1.0 & 0.8492 & $<0.0001$ & $<0.0001$ & $<0.0001$ & $<0.0001$ & 0.2002 \\
\hline 1.5 & $<0.0001$ & $<0.0001$ & $<0.0001$ & $<0.0001$ & $<0.0001$ & $<0.0001$ \\
\hline 2.0 & $<0.0001$ & $<0.0001$ & $<0.0001$ & $<0.0001$ & $<0.0001$ & $<0.0001$ \\
\hline 2.5 & $<0.0001$ & $<0.0001$ & $<0.0001$ & $<0.0001$ & $<0.0001$ & 0.8390 \\
\hline 3.0 & $<0.0001$ & $<0.0001$ & $<0.0001$ & $<0.0001$ & $<0.0001$ & 0.1384 \\
\hline 3.5 & $<0.0001$ & $<0.0001$ & $<0.0001$ & $<0.0001$ & $<0.0001$ & 0.9858 \\
\hline 4.0 & $<0.0001$ & $<0.0001$ & $<0.0001$ & $<0.0001$ & $<0.0001$ & 0.8195 \\
\hline 4.5 & $<0.0001$ & $<0.0001$ & $<0.0001$ & $<0.0001$ & $<0.0001$ & 0.0618 \\
\hline 5.0 & $<0.0001$ & $<0.0001$ & $<0.0001$ & $<0.0001$ & $<0.0001$ & 0.9998 \\
\hline \multirow{2}{*}{ 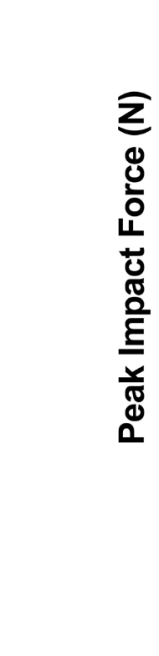 } & $000=$ & & & & $\begin{array}{l}\text { SBLI } \\
\text { ARLI } \\
\text { Std } 10 \mathrm{oz} \\
\text { Std } 16 \mathrm{oz}\end{array}$ & \\
\hline & -2.0 & $\begin{array}{r}-1.5 \\
\text { Peak } 1\end{array}$ & (m.sec $^{-1}$ & $\begin{array}{l}\text { e Acce } \\
\sec ^{-1} \text { ) }\end{array}$ & $\begin{array}{l}5 \\
\text { ation }\end{array}$ & 0.0 \\
\hline
\end{tabular}

Figure 21. Effect of glove type on relationship of peak negative glove deceleration during compressive phase of glove impact with force plate to peak recorded impact force. 
Table 13. Results of Tukey post-hoc comparisons between glove types for slope of the linear relationship between peak glove deceleration during the compressive phase and measured peak impact force. Each cell shows the probability that there was no real difference between glove types. Red figures indicate a statistically significant difference and blue figures indicate absence of significance $(\mathrm{P}>0.05)$.

\begin{tabular}{cc}
\hline Comparison & Probability \\
\hline SBLI vs ARLI & $<0.0001$ \\
SBLI vs Std $10 \mathrm{oz}$ & 0.0528 \\
SBLI vs Std $16 \mathrm{oz}$ & 0.0015 \\
ARLI vs Std $10 \mathrm{oz}$ & $<0.0001$ \\
ARLI vs Std $16 \mathrm{oz}$ & 0.0028 \\
Std $10 \mathrm{oz}$ vs Std $16 \mathrm{oz}$ & 0.6798 \\
\hline
\end{tabular}

was significantly or almost significantly greater than that for the other gloves, even though this glove had the lowest mass. No significant difference could be detected between the Std $10 \mathrm{oz}$ and Std $16 \mathrm{oz}$ gloves. The fact that the magnitude of change in peak impact force for a given change in peak glove deceleration varied between gloves suggests that any error stemming from use of independent methods to determine deceleration and peak force differed systematically as a function of glove type.

Nevertheless, when the data shown in Figure 21 were treated as a single data set with all observations for all glove types included, a second order polynomial regression equation yielded an $\mathrm{R}^{2}$ value of 0.9661 , indicating that more than $96 \%$ of the variance in peak impact force could be explained in terms of peak whole-glove deceleration during the compressive phase of impact.

In a previous publication reporting on data that did not incorporate glove velocity measures, we noted that force plate contact time was the best predictor of peak impact force for a conventional $10 \mathrm{oz}$ glove while time from initial force plate contact to occurrence of peak force was the best predictor for an ARLI glove [4]. Figure 22 shows that in the current study, too, these variables were strong predictors of peak impact force for each individual glove type, with $\mathrm{R}^{2}$ values always exceeding 0.96 . When observations on all gloves were treated as a single data set, however, the $\mathrm{R}^{2}$ value for a second order polynomial regression equation expressing the relationship of contact time to peak force was 0.4835 , while that for the relationship between time to peak force and the magnitude of the peak force was 0.4997 . While these associations were statistically significant $(\mathrm{P}<0.0001)$, they were considerably weaker than the abovementioned relationship between peak whole-glove deceleration during the compressive phase of impact and peak impact force. It is visually evident that glove type affected the relationship depicted in Figure 21 much less than it influenced that shown in Figure 22.

\section{Discussion}

A major finding of this study was that, following impact with a target, the pneumatic 

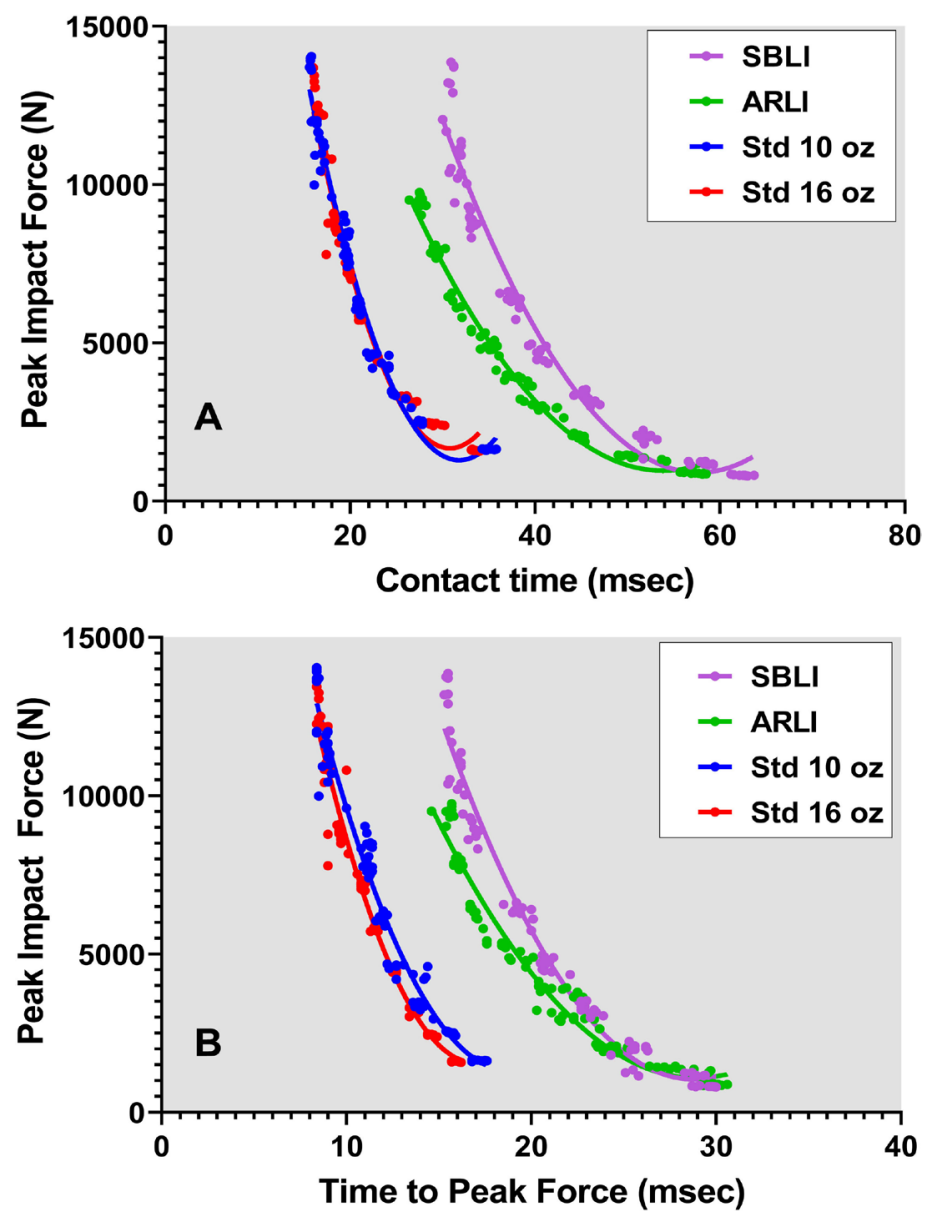

Figure 22. Relationship of glove contact time with force plate (Panel A) and time from initial glove contact with force plate to occurrence of peak force (Panel B) to peak impact force for different glove types. Note that the highest peak impact force recorded was substantially lower for the ARLI glove.

gloves (SBLI and ARLI) decelerated to zero velocity more slowly than the conventional gloves (Std $10 \mathrm{oz}$ and Std $16 \mathrm{oz}$ ). This was true at all drop heights. A similar trend was observed for peak glove deceleration, which in keeping with theoretical expectations [14] always occurred in the instant before attainment of zero velocity.

Whereas the kinematics of the two conventional gloves during the compressive phase of impact were generally alike, there were differences between the two pneumatic gloves as a function of drop height. The time to reach zero velocity tended to be longer for the SBLI glove than the ARLI glove at lower drop heights, with the reverse occurring at higher drop heights. For the ARLI glove, peak deceleration was significantly less than that for the SBLI glove at drop heights of 3 metres and above.

Transfer of momentum between two colliding objects causes one or both to undergo a positive or negative change in velocity [15]. The rate of the velocity change (i.e., the acceleration) influences the risk of damage to the objects. For example, it is known that severity of concussive injury resulting from head im- 
pacts is directly related to the peak magnitude of linear and/or rotational acceleration of the head [16] [17] [18]. Interventions that reduce peak accelerations by extending velocity change over a longer period can reportedly reduce the severity of attendant damage [19] [20]. Consequently, the ability of our pneumatic gloves to exert that effect is evidently a positive feature, with the ARLI glove performing better than any of the others when pre-impact glove velocities were moderate to high.

Introduction of cushioning elements is often used as a means of limiting accelerations resulting from collisions [21]. The efficacy of these elements depends on both their thickness and their material properties [22]. For any given cushioning element, increasing thickness provides greater accelerative damping. For any given thickness, more compliant materials (i.e. materials capable of greater deformation in response to a standard applied force) yield better outcomes as long as the limits of their compliance are not exceeded such that they "bottom out". In practice, most cushioning elements undergo dynamic change in compliance during compression [14], becoming progressively stiffer [23]. The final level of stiffness is another determinant of peak deceleration.

In their resting state, the pneumatic gloves had substantially thicker padding than the conventional gloves. Also, the contact surfaces of the pneumatic gloves were softer than those of the conventional gloves. These differences provided the pneumatic gloves with greater overall scope for compression, a characteristic demonstrated by our glove displacement data. The greater scope for compression probably explains the longer time to attainment of zero velocity, with the distribution of impact energy over this longer time accounting for the lower peak acceleration measurements.

The incorporation of an air release mechanism into the ARLI glove appears to have conferred it with material properties different from those of the SBLI glove, perhaps by reducing build-up of dynamic stiffness of the cushioning layer at higher levels of impact energy and enabling greater glove compression. While both pneumatic gloves showed reduced displacement as drop height increased beyond 2 metres, the reduction was less for the ARLI glove. This suggests a lesser effect of internal build-up of air pressure.

The duration of the rebound phase of impact was also significantly longer for the pneumatic gloves compared to the conventional gloves, with this difference observed at every drop height. For each glove type, the duration of the rebound phase was always less than the duration of the compressive phase, but the ratio of rebound duration to compression duration increased as drop height increased. There are at least two possible explanations for the latter finding. Serial increases in impact energy may have damaged gloves in a way that progressively reduced both their resistance to compression and their subsequent resilience, thereby making compression relatively faster and rebound relatively slower. It is equally conceivable that the ratio of rebound duration to compression duration was an indicator of the proportion of impact energy retained during collision following 
some conversion of energy to other sources such as heat, sound and padding deformation. Greater proportional energy retention during the compressive phase would result in greater proportional energy availability to drive the rebound phase, favouring relative prolongation of rebound. In this respect, it is notable that the ratio of rebound duration to compression duration was always lower for the ARLI glove than for any of the other gloves, except at a drop height of 5 metres, where it became similar to that for the Std $10 \mathrm{oz}$ and Std 16 oz gloves. By contrast, the ratio for the SBLI glove was lower than that for the Std $10 \mathrm{oz}$ and Std 16 oz gloves at low drop heights, but at the 5-metre drop height the SBLI glove produced the highest ratio.

To further investigate the above possibilities, it is instructive to first look at the classical index of energy retention, which is the coefficient of restitution [8] [9] [10] [15]. This index has been variously calculated though use of kinematic, dynamic and energetic parameters and under many circumstances the three different approaches yield equivalent findings [11]. The kinematic coefficient of restitution of an object is defined as the ratio of its peak rebound velocity to its peak pre-impact velocity [8] [9] [10], and we used this definition for the purpose of the current study. The ARLI glove was found to have the lowest coefficient of restitution at drop heights up to and including 3 metres. Beyond that point, its advantage over the Std $10 \mathrm{oz}$ and Std $16 \mathrm{oz}$ gloves was lost. The SBLI glove yielded the highest coefficients of restitution at all drop heights from 2 metres onwards. It can be surmised that when impact energy levels were low to moderate, the ARLI glove was the most effective in enabling conversion of the energy to other forms, probably including heat generated through friction associated with egress and subsequent ingress of air through the air exchange aperture unique to that glove. It seems likely that the sealed nature of the bladder in the SBLI glove led to greater storage of potential energy in the form of air compression, and subsequent return to kinetic energy during rebound.

In a previous paper describing other aspects of the experiment reported here, we noted that the area under the force-time curve was surprisingly high for the SBLI glove given its comparatively low mass [1]. We made the same observation in a subsequent paper concerning a study in which SBLI, ARLI, Std 10 oz and Std $16 \mathrm{oz}$ gloves were dropped from various heights on to a force plate covered by a thicker EVA mat [2]. The current finding that, overall, the SBLI glove had the highest coefficient of restitution offers an explanation for these earlier results.

An interesting finding of our research was that, for all gloves, the coefficient of restitution initially increased as a function of drop height before reaching a stable value. This contrasts with multiple reports showing that for solid objects involved in collisions there is a reduction in the coefficient as pre-impact velocity increases [8] [9] [10] [11]. There has been one report [11] showing that for objects with relatively low stress yield points, even a single collision can produce plastic deformation that permanently alters the material properties of the object and decreases its compliance, with this leading to a higher coefficient of restitu- 
tion for subsequent standardised impacts. Further changes in the same direction occur with repeated impacts, before a plateau is finally reached. The fact that increasing drop height initially produced an increase in the coefficient of restitution of our gloves, rather than the expected decrease, suggests a high likelihood that the material properties of the gloves were progressively altered as impact energy increased. For the Std $10 \mathrm{oz}$ and Std $16 \mathrm{oz}$ gloves, the alteration may have reflected degradation of the foam padding, whereas for the SBLI and ARLI gloves it may have been due to rise of air pressure within the glove bladder. In the case of the ARLI glove, it is probable that at very high impact energy levels the ability of the air exchange mechanism to prevent build-up of high air pressure levels within the bladder was overwhelmed. In the future, this could perhaps be prevented by increasing the size of the air exchange aperture to reduce the resistance to air flow. Alternatively, the existing aperture could be supplemented by addition of another much smaller one that presumably would be brought into play only when bladder air pressure became high enough to overcome its inherent flow resistance. This alternative may be preferable as a means of optimising the performance of the glove over the whole range of impact energy levels that it could encounter. Scope also exists to experiment with aperture shapes as a means for "tuning" ARLI gloves for performance in different situations.

If degradation of glove structural materials contributed to the observed change in the ratio of rebound duration to compression duration as a function of drop height, such that gloves tended to compress more quickly and rebound more slowly, it could be expected that the negative slopes of glove acceleration-time curves for the compressive and rebound phases would become progressively more dissimilar as drop heights increased. We found that, for each glove individually, the slopes were close to identical at drop heights up to and including 2.5 metres. This similarity indicated that the slopes were likely determined primarily by glove material properties, with the kinematics of the compression phase having a strong hysteretic influence on those of the rebound phase. For the ARLI glove, no significant difference between the compression and rebound slopes could be detected until a drop height of 4.5 metres, at which point the deceleration slope for the rebound phase became less than that for the compressive phase in line with the above hypothesis. For the other gloves, this trend became statistically detectable at a drop height of 3.5 metres, and eventual disparity between the compression and rebound slopes was greater. Overall, our observations were consistent with the notion that all gloves could have suffered some structural degradation at higher drop heights, with the degradation being least for the ARLI glove. It is salient that we recently reported a study in which ARLI and Std $10 \mathrm{oz}$ gloves were each dropped 250 times on to force plate from a height of 3 metres, and that while both gloves were associated with upward drift in peak force and loading rate over the drop series, these effects were much smaller for the ARLI glove.

We attempted to focus intensively on energy transfer occurring during the brief 
period of transition from glove compression to glove rebound by developing an index that compared the absolute values of peak glove deceleration during compression and peak glove acceleration during rebound and expressed the difference as a proportion of the former value. Qualitatively, use of the index suggested conclusions quite similar to those derived from calculating the kinematic coefficient of restitution, in that the ARLI glove seemed to facilitate greater energy dissipation than the conventional gloves when the impact energy level was low to moderate but not when it was high, while the SBLI glove produced the least energy dissipation across most of the range of impact energy levels included in the experiment. This similarity is not surprising, since peak pre-impact glove velocity (the denominator in the calculation of the kinematic coefficient of restitution) influences the velocity of glove compression and therefore the peak deceleration, while peak glove acceleration at the beginning of rebound and peak rebound velocity (the numerator in the calculation of the kinematic coefficient of restitution) are closely related parameters. Nevertheless, increasing drop height produced different patterns of change in the index based on the peak acceleration and deceleration readings compared to those observed for the coefficient of restitution. For the pneumatic gloves, the acceleration index showed hyperbolic progression as a function of drop height, systematically decreasing before increasing, while for the conventional gloves there was a much more linear progression. In the case of the kinematic coefficient of restitution, all gloves showed an initial rise as a function of drop height, followed by stabilisation.

The slightly different findings for the two indices are likely due to two factors. Firstly, calculation of the kinematic coefficient of restitution entails use of one variable (peak pre-impact velocity) that is essentially a direct measure of the kinetic energy applied to the system and one (peak rebound velocity) that is an outcome of remaining kinetic energy after the collision. For the index based on peak acceleration and deceleration values, both variables used in the calculation are outcomes of the application of kinetic energy. Secondly, the coefficient of restitution is determined over the whole period of the collision from initial contact to attainment of peak rebound velocity, whereas the peak acceleration/deceleration index focused more narrowly on the period of transition from compression to rebound.

If the index based on the peak acceleration and deceleration is accepted as valid, some interesting implications emerge. The initial decrease observed for both pneumatic gloves with increasing drop height could reflect a reduction in proportional energy dissipation as impact energy levels increase, in keeping with findings reported elsewhere in the scientific literature [8] [10] [11] [15] [24]. Subsequent increase in the index at drop heights of 4.5 and 5 metres might reflect occurrence of structural and/or functional changes to the gloves when impact levels are high. For the conventional gloves, the existence of a positive linear relationship between the index and drop height could be interpreted as indicating progressive structural change, perhaps due to gradual compression of foam padding. It has 
been reported that objects compressed through repeated collisions have reduced capacity for energy dissipation, causing increase in the coefficient of restitution [11].

Based on the above, it can be inferred that the pneumatic gloves underwent little or no unrecovered deformation at drop heights up to and including 4 metres, while the conventional gloves were subject to some persistent deformation even at the lowest drop heights. Lee and McGill [25] found that when a mechanised device was used to deliver 10,000 standardised impacts from a conventional $16 \mathrm{oz}$ glove to a force transducer, the peak impact force showed upward drift of $\sim 40 \%$ over the series, even though the impact velocity was low. Most of the drift occurred during the first 2000 impacts and was speculatively attributed to deformation of glove padding materials, with resultant increase in the stiffness of the padding reducing its capacity for energy dissipation upon impact.

The use of air compression rather than fabric compression as the primary impact buffering mechanism of the pneumatic gloves may have made them more resistant to unrecovered deformation. Our data suggest that at drop heights of 4.5 and 5 metres, some unrecovered deformation may have occurred. It is conceivable that in the ARLI glove, the foam used to form the bladder "skeleton" became somewhat compressed. It is notable, however, that the rise in the peak acceleration/deceleration index from the 4-metre to 5-metre drop heights was greater for the SBLI glove, which had no bladder skeleton, than for the ARLI glove. Compression of a foam layer that formed an interface between the mechanical fist and the bladder therefore seems a more likely reason for the increase in the index, since that layer was common to both pneumatic gloves. A possibility also exists that there was no material degradation in the pneumatic gloves and that increased stiffness at higher drop heights was related simply to exponential increase in bladder air pressure. Further research will be needed to investigate the alternative explanations.

Another intriguing finding of our research was the difference between glove types in terms of the temporal relationship between velocity curves and force curves. We had a priori expectations that, for each glove type, attainment of zero glove velocity at the end of impact-induced compression would coincide with measured peak impact force, and that peak rebound velocity would occur very soon after the end of glove contact with the force plate. Our inability to confirm these expectations was not attributable to lack of synchrony between our force and velocity measurements, since the two data streams were simultaneously collected by the same software package to ensure temporal matching. Nor were the apparent anomalies due to our use of regression models to calculate the time of zero glove velocity, since mean calculated times were very close to the mean times at minimum observed glove velocity, with the latter likely to provide a good indication of time to zero velocity because of random distribution of observed values around the true zero point.

For the pneumatic gloves, our expectation of close temporal alignment be- 
tween attainment of zero glove velocity at the end of compression and occurrence of peak impact force was close to being met, at least at drop heights of 2.5 metres and above. For the conventional gloves, however, peak impact force substantially preceded zero glove velocity at every drop height. On first consideration, it is difficult to understand how this could be the case, as it seems inconsistent with Newton's second law of motion, which indicates that the force acting on an object is the product of its mass and its acceleration. Integration of our velocity data produced curves indicating that peak negative acceleration during glove compression occurred at almost the same instant as zero glove velocity, a result in keeping with theoretical paradigms [14]. With glove mass remaining constant, and force exerted by the glove on the force plate therefore entirely dependent on its acceleration, it can be deduced that peak glove force must always have very close temporal proximity to the zero-velocity point.

We can only speculate on a possible explanation for our finding for the conventional gloves. We measured glove velocity during compression by using a Vicon Motion Capture System to determine the rate at which the vertical distance between markers placed at different points on the glove surface decreased following impact. The measurement was therefore indicative of whole glove velocity, but each glove consisted of a series of linked components, and it is conceivable that some of these followed different velocity curves. Based on existing scientific literature, it is reasonable to surmise that the polyurethane foam padding of the conventional gloves may have been highly anisotropic [26] [27]. Directional variation in the properties of the padding could predispose it to some lateral expansion after the centre of mass of the glove has reached zero vertical velocity. This lateral expansion would cause continued decrease in the vertical distance between markers on the glove surface. It can be envisaged that peak impact force might coincide with zero velocity of the glove centre of mass, while zero velocity of the whole glove as determined by the Vicon Motion Capture system might coincide with subsequent completion of lateral expansion of the padding. Given that the padding of the pneumatic gloves consisted primarily of an air-containing bladder, it could be expected to exhibit a more isotropic characteristic, resulting in closer temporal correspondence between compression and lateral expansion.

Our data also revealed significant differences between gloves in terms of temporal alignment between the end of force plate contact (as indicated by measurements obtained from the force plate) and the attainment of peak glove rebound velocity (as determined through analysis of measurements provided by the Vicon Motion Capture System). For both conventional gloves, peak rebound velocity occurred well after the end of force plate contact, with the interval being $\sim 10 \mathrm{msec}$ at a drop height of 1 metre and still $\sim 4 \mathrm{msec}$ at a drop height of $5 \mathrm{me}-$ tres. For the ARLI glove, by contrast, the two events were close to simultaneous at drop heights of 2.5 metres and above. In the case of the SBLI glove, peak rebound velocity occurred before the end of force plate contact at all drop heights 
from 2 metres upwards, despite this glove having the highest peak rebound velocities. At the 5-metre drop height, the time by which peak rebound velocity preceded the end of force plate contact reached $\sim 5 \mathrm{msec}$. The difference between the conventional gloves and the pneumatic gloves could be largely due to the former having thinner padding and therefore smaller displacement of the padding during the rebound phase. Limitations on the magnitude of rebound displacement would restrict the period for which contact of the glove with the force plate could potentially be maintained.

The observation that at all but the lowest drop heights the SBLI glove reached peak rebound velocity before cessation of its contact with the force plate can be explained by the fact that this glove not only had considerable scope for rebound displacement, but also had the greatest energy storage during compression, as reflected by its high coefficient of restitution. This greater energy storage evidently caused relatively early initiation of rebound and allowed the process to reach an advanced stage while the glove was still in contact with the force plate. Calculations based on our data show that rebound did commence at a proportionally earlier stage of force plate contact for the SBLI glove than for any of the other gloves. When time to rebound commencement was expressed as a proportion of total force plate contact time, averaging across all drop heights produced values of $0.514,0.584,0.809$, and 0.778 for the SBLI, ARLI, Std $10 \mathrm{oz}$ and Std 16 oz gloves respectively.

Notwithstanding interpretive issues raised by apparent temporal misalignments of key kinematic and kinetic variables, our finding of a very high correlation between peak glove deceleration during compression and peak impact force is simply consistent with Newton's second law of motion. Variance in peak glove deceleration calculated from Vicon data was able to account for more than $95 \%$ of the variance in peak impact force measured by the force plate, with this being true not just for each glove individually, but even for all gloves collectively. In the latter respect, the calculated peak glove deceleration was much more strongly related to peak impact force than was the case for either the total duration of force plate contact or the time from initial force plate contact to occurrence of peak force. The slope of a linear regression curve obtained when data from all gloves were included in a single analysis indicated that for every reduction of $1 \%$ in peak deceleration there was a decrease of $1.046 \%$ (95\% confidence interval 1.001 to 1.091 ) in peak force, a result obviously very close to unity and consistent with the theoretical expectation of a directly causal relationship.

It is noteworthy that small but statistically significant differences between gloves regarding the relationship between calculated whole-glove deceleration during compression and peak impact force were not explicable in terms of the classical Newtonian principle that force is the product of mass and acceleration. Indeed, for any given level of peak negative acceleration the SBLI glove tended to produce the highest peak forces, despite having the lowest mass. Also, the ARLI glove tended to produce the lowest values, despite having greater mass than ei- 
ther the SBLI or Std $10 \mathrm{oz}$ gloves. Since coefficients of restitution were highest for the SBLI glove and lowest for the ARLI glove, it may be that our measures of peak glove deceleration were affected in some way by the amount of energy converted to other forms during the impact. It is possible that differences between gloves in impact biomechanics affected relative rates of displacement of markers positioned on the glove surfaces and monitored by the Vicon Motion Capture System. Even so, it is evident that the method we employed for determining peak glove deceleration is sufficiently accurate to make it suitable for future assessment of the impact-buffering capacity of pneumatic gloves in field situations where direct measurement of impact forces may be impractical.

It is obviously important to understand the mechanisms by which pneumatic gloves such as those used in the present study can reduce peak deceleration during compression (and therefore peak impact force). Vital mechanisms seem to include greater absolute scope for compression (due to increased padding thickness and lower initial stiffness of the padding) and capacity for air exchange with the external environment as a means for impact energy dissipation. Our ARLI glove is clearly superior to the SBLI glove in terms of integrating these mechanisms.

In a previous publication [28], we summarised contemporary arguments for and against boxing. The principal objections to the sport include the attendant risk of serious acute and/or cumulative injury. There have been suggestions that development of boxing gloves capable of substantially reducing peak impact forces could be a means of decreasing the risk [29]. The findings reported in this paper and elsewhere demonstrate that development of impact-buffering gloves is achievable, with our ARLI glove providing strong proof of concept.

It has been pointed out the relationship between percentage reduction in variables such as acceleration and the percentage reduction in injury risk is sigmoid rather than linear [22]. The implication is that decreasing the acceleration/deceleration associated with an impact by a specific percentage may not necessarily decrease injury risk by that same percentage. In situations where the probability of injury is either very high or very low, even a reduction of $30 \%$ in the acceleration parameter may have little effect on injury incidence or severity. On the other hand, the sigmoid curve shape means that there are some circumstances in which a $30 \%$ reduction in acceleration could diminish the injury risk by more than that amount.

The present study shows that the ARLI glove attenuates peak glove deceleration during the compressive phase of impact, and associated peak impact forces, by $\sim 20 \%-35 \%$ across the whole range of pre-impact glove velocities extending from $\sim 4.4 \mathrm{~m} \cdot \mathrm{sec}^{-1}$ (at a drop height of 1 metre) to $\sim 10 \mathrm{~m} \cdot \mathrm{sec}^{-1}$ (at a drop height of 5 metres). The latter is close to the maximum glove velocity that can be generated by elite boxers [5] [6] [7], but a study that involved measurement of impact forces during professional boxing matches suggests a high likelihood that the great majority of impacts entail much lower velocities [30]. We do not yet know whether use of ARLI gloves would decrease incidence and/or severity of 
boxing injuries caused by very high velocity impacts, but there is reason to believe that at the very least they could substantially reduce injury risks resulting from impacts of moderate velocity. This is potentially important given that such impacts may contribute substantially to cumulative, chronic injuries. It has been reported, for example, that long-term exposure to repeated sub-concussive impacts may cause brain injury and reduced cognitive function in American footballers [31].

Our development of pneumatic boxing gloves is taking place in the context of efforts to support a modified form of boxing in which impacts to the head and neck, and any high-velocity impacts, are prohibited. Feedback from modified boxing participants who have used the ARLI gloves has been very positive [32] and indicative of a perception that the gloves are effective in reducing impact forces. The gloves could undoubtedly be improved through further iteration guided by insights such as those gained through the research described in this paper. We hope that publication of the paper will encourage others to take up the ongoing design and development challenge, whether in collaboration with us or independently.

\section{Conclusion}

It is possible to develop boxing gloves that are no larger than conventional gloves but decelerate more slowly following contact with a target and mitigate both peak impact forces and loading rates. Such gloves have potential to reduce the incidence and severity of boxing injuries, although their impact buffering capabilities may not be enough to prevent injury when impact velocities are very high. Progress is being made in understanding the glove design elements that are critical to the protective effect. The use of air as a cushioning material shows great promise provided it is implemented in combination with a mechanism allowing some air release upon impact and subsequent air reuptake. Optimisation of the air exchange mechanism will be a critical task and customised solutions may be required to cater for use of the gloves in various situations. Producing pneumatic gloves in a form that more closely resembles conventional gloves could well increase their uptake but any reduction in the thickness of the air cushioning layer would almost certainly reduce the protective effect unless compensated by other means. Recent and ongoing emergence of modified forms of boxing might provide both a stimulus for further iteration of safer boxing gloves and a vehicle for real-world evaluation and refinement of their design.

\section{Acknowledgements}

The research reported in this paper was supported by grants from the Australian Olympic Committee (through the international Olympic Solidarity Program) and the Queensland Academy of Sport. Luke and Katie Eldridge manufactured the mechanical fist used in the research. Anthony Ashmore of AJA Engineering, Bill Shelley and Associate Professor Stephen Trathen of the University of Canberra, 
Jamie Plowman and Michael Steinebronn of the Australian Institute of Sport, and Dr Richard Helmer of Superinteractive Pty Ltd provided valuable technical assistance and advice. Dr Christopher Barnes of the University of Canberra helped with data collection. The Canberra Police Community Youth Club encouraged the first author of this paper to pursue the development of impact-buffering boxing gloves while he was in its employ.

\section{Dedication}

This paper is dedicated to the memory of Mr Jalaj Anand, who was enthusiastic about the potential of the pneumatic boxing gloves and, subsequent to the research reported here, oversaw manufacture of several batches of the gloves through his family company, Paramount Enterprises, in Dehradun, northern India. He was in the prime of his life when he was lost to a tragic accident, and is greatly missed by all who knew him.

\section{Conflicts of Interest}

The authors declare no conflicts of interest regarding the publication of this paper.

\section{References}

[1] Perkins, P., Jamieson, A., Spratford, W. and Hahn, A. (2018) Evaluation of Ability of Two Different Pneumatic Boxing Gloves to Reduce Delivered Impact Forces and Improve Safety. World Journal of Engineering and Technology, 6, 457-491. https://doi.org/10.4236/wjet.2018.62028

[2] Perkins, P., Jamieson, A., Spratford, W. and Hahn, A. (2018) Performance of Prototype Pneumatic Boxing Gloves under Two Different Conditions of Target Padding. World Journal of Engineering and Technology, 6, 603-624. https://doi.org/10.4236/wjet.2018.63037

[3] Perkins, P., Jamieson, A., Ferguson, G., Spratford, W. and Hahn, A. (2018) Iterative Design of Impact-Damping Gloves for Safer Boxing. Open Journal of Safety Science and Technology, 8, 49-97. https://doi.org/10.4236/ojsst.2018.83005

[4] Perkins, P., Jamieson, A., Spratford, W. and Hahn, A. (2019) Pneumatic Boxing Glove Reduces Upward Drift in Peak Force and Loading Rate over a Long Series of Impacts. World Journal of Engineering and Technology, 7, 18-53.

https://doi.org/10.4236/wjet.2019.71002

[5] Walilko, T.J., Viano, D.C. and Bir, C.A. (2005) Biomechanics of the Head for Olympic Boxer Punches to the Face. British Journal of Sports Medicine, 39, 710-719.

https://doi.org/10.1136/bjsm.2004.014126

[6] Viano, D.C., Casson, I.R., Pellman, E.J., Bir, C.A., Zhang, L., Sherman, D.C., et al. (2005) Concussion in Professional Football: Comparison with Boxing Head Impacts-Part 10. Neurosurgery, 57, 1154-1172. https://doi.org/10.1227/01.NEU.0000187541.87937.D9

[7] Piorkowski, B.A., Lees, A. and Barton, G.B. (2011) Single Maximal versus Combination Punch Kinetics. Sports Biomechanics, 10, 1-11. https://doi.org/10.1080/14763141.2010.547590

[8] Kharaz, A.H. and Gorham, D.A. (2000) A Study of the Restitution Coefficient in 
Elastic-Plastic Impact. Philosophical Magazine Letters, 80, 549-559. https://doi.org/10.1080/09500830050110486

[9] Aryaei, A., Hashemnia, K. and Jafarpur, K. (2010) Experimental and Numerical Study of Ball Size Effect on Restitution Coefficient in Low Velocity Impacts. International Journal of Impact Engineering, 37, 1037-1044.

https://doi.org/10.1016/j.ijimpeng.2010.04.005

[10] Haron, A. and Ismail, K.A. (2012) Coefficient of Restitution of Sports Balls: A Normal Drop Test. IOP Conference Series. Materials Science and Engineering, 36, Article ID: 012038. https://doi.org/10.1088/1757-899X/36/1/012038

[11] Seifried, R., Schiehlen, W. and Eberhard, P. (2005) Numerical and Experimental Evaluation of the Coefficient of Restitution for Repeated Impacts. International Journal of Impact Engineering, 32, 508-524. https://doi.org/10.1016/j.ijimpeng.2005.01.001

[12] International Boxing Association (2017) AIBA Technical Rules: Effective as of April 26. http://www.aiba.org/aiba-technical-competition-rules/

[13] Kell, L. (2016) A Guide to Boxing Gloves. https://www.newitts.com/blog/a-guide-to-boxing-gloves?country=

[14] Fiedler, R.M. (1988) Predicting Minimum Cushion Thickness. In: Current Trends in Protective Packaging of Computers and Electronic Components. ASTM STP994, American Society for Testing and Materials, Philadelphia, PA, 33-42. https://doi.org/10.1520/STP26372S

[15] Gilardi, G. and Sharf, I. (2002) Literature Survey on Contact Dynamics Modelling. Mechanism and Machine Theory, 37, 1213-1239. https://doi.org/10.1016/S0094-114X(02)00045-9

[16] McLean, A.J. and Anderson, R.W.G. (1997) Biomechanics of Closed Head Injury. In: Head Injury: Pathophysiology and Management, Chapman \& Hall Medical, London, 25-37.

[17] Meaney, D.F. and Smith, D.H. (2011) Biomechanics of Concussion. Clinical Journal of Sport Medicine, 30, 19-31. https://doi.org/10.1016/j.csm.2010.08.009

[18] Kleiven, S. (2013) Why Most Traumatic Brain Injuries Are Not Caused by Linear Acceleration But Skull Fractures Are. Frontiers in Bioengineering and Biotechnology, 1, 1-5. https://doi.org/10.3389/fbioe.2013.00015

[19] Oeur, R.A. and Hoshizaki, T.B. (2016) The Effect of Impact Compliance, Velocity, and Location in Predicting Brain Trauma for Falls in Sport. Proceedings of the IRCOBI 2016 Conference International Research Council on Biomechanics of Injury, Malaga, Spain, 14-16 September 2016, 228-238.

[20] Hoshizaki, B., Post, A., Kendall, M., Karton, C. and Brien, S. (2013) The Relationship between Head Impact Characteristics and Brain Trauma. Journal of Neurology \& Neurophysiology, 5, 181. https://doi.org/10.4172/2155-9562.1000181

[21] Shorten, M. (2000) Running Shoe Design: Protection and Performance. In: Marathon Medicine, Royal Society of Medicine Press, London, 159-169.

[22] Committee on Sports-Related Concussions in Youth (2014) Protection and Prevention Strategies. In: Sports-Related Concussions in Youth: Improving the Science, Changing the Culture, The National Academic Press, Washington DC, 239-384.

[23] White, S.W., Kim, S.K., Bajaj, A.K., Davies, P., Showers, D.K. and Liedtke, P.E. (2000) Experimental Techniques and Identification of Nonlinear and Viscoelastic Properties of Flexible Polyurethane Foam. Nonlinear Dynamics, 22, 281-313. https://doi.org/10.1023/A:1008302208269

[24] Seifried, R., Schiehlen, W. and Eberhard, P. (2010) The Role of the Coefficient of Res- 
titution on Impact Problems in Multi-Body Dynamics. Proceedings of the Institution of Mechanical Engineers, Part K: Journal of Multi-Body Dynamics, 224, 279-306. https://doi.org/10.1243/14644193JMBD239

[25] Lee, B. and McGill, S. (2014) Striking Dynamics and Kinetic Properties of Boxing and MMA Gloves. Revista de Artes Marciales Asiáticas, 9, 106-115. https://doi.org/10.18002/rama.v9i2.1175

[26] Huber, A.T. and Gibson, L.J. (1988) Anisotropy of Foams. Journal of Materials Science, 23, 3031-3040. https://doi.org/10.1007/BF00547486

[27] Lee, T. and Lakes, R.S. (1997) Anisotropic Polyurethane Foam with Poisson's Ratio Greater Than 1. Journal of Materials Science, 32, 2397-2401. https://doi.org/10.1023/A:1018557107786

[28] Perkins, P., Hahn, A., Lucas, R. and Keegan, R. (2014) The Boxing Conundrum: Is There a Place for a New Variant of the Sport? Journal of Research in Humanities and Social Science, 2, 9-25.

[29] American Medical Association (1999) Boxing Injuries.

[30] Pierce, J.D., Reinbold, K.A., Lyngard, B.C., Goldman, R.J. and Pastore, C.M. (2006) Direct Measurement of Punch Force during Six Professional Boxing Matches. Journal of Quantitative Analysis in Sports, 2, 1-17. https://doi.org/10.2202/1559-0410.1004

[31] Amen, D., Newberg, A., Thatcher, R., Jin, Y., Wu, J., Keator, D., et al. (2011) Impact of Playing American Professional Football on Long-Term Brain Function. The Journal of Neuropsychiatry and Clinical Neurosciences, 23, 98-106.

https://doi.org/10.1176/appi.neuropsych.23.1.98

[32] Perkins, P. and Hahn, A. (2019) Factors Underpinning at Least Three Years of Participant Adherence to a Community-Focused Modified Boxing Program. Open Journal of Social Sciences, 7, 298-331. https://doi.org/10.4236/jss.2019.72023 